\title{
Self-Assembling Peptides as an Emerging Platform for the Treatment of Metabolic Syndrome
}

This article was published in the following Dove Press journal:

International Journal of Nanomedicine

\author{
Luis Alberto Castillo-Díaz (D) \\ Juan Alberto Ruiz-Pacheco (iD ${ }^{2}$ \\ Mohamed Ahmed Elsawy $\mathbb{1 D}^{3}$ \\ Juana Elizabeth Reyes- \\ Martínez (iD) 4 \\ Andrea Isabel Enríquez- \\ Rodríguez' \\ 'Department of Medicine and Health \\ Sciences, University of Sonora, \\ Hermosillo, Sonora, Mexico; ${ }^{2}$ West \\ Biomedical Research Center, National \\ Council of Science and Technology, \\ Guadalajara, Jalisco, Mexico; ${ }^{3}$ Leicester \\ Institute for Pharmaceutical Innovation, \\ Leicester School of Pharmacy, De \\ Montfort University, Leicester, \\ Leicestershire, UK; ${ }^{4}$ Department of \\ Biology, University of Guanajuato, \\ Guanajuato, Guanajuato, Mexico
}

\begin{abstract}
Metabolic syndrome comprises a cluster of comorbidities that represent a major risk of developing chronic diseases, such as type II diabetes, cardiovascular diseases, and stroke. Alarmingly, metabolic syndrome reaches epidemic proportions worldwide. Today, lifestyle changes and multiple drug-based therapies represent the gold standard to address metabolic syndrome. However, such approaches face two major limitations: complicated drug therapeutic regimes, which in most cases could lead to patient incompliance, and limited drug efficacy. This has encouraged scientists to search for novel routes to deal with metabolic syndrome and related diseases. Within such approaches, self-assembled peptide formulations have emerged as a promising alternative for treating metabolic syndrome. In particular, self-assembled peptide hydrogels, either as acellular or cell-load three-dimensional scaffoldings have reached significant relevance in the biomedical field to prevent and restore euglycemia, as well as for controlling cardiovascular diseases and obesity. This has been possible thanks to the physicochemical tunability of peptides, which are developed from a chemical toolbox of versatile amino acids enabling flexibility of designing a wide range of self-assembled/co-assembled nanostructures forming biocompatible viscoelastic hydrogels. Peptide hydrogels can be combined with several biological entities, such as extracellular matrix proteins, drugs or cells, forming functional biologics with therapeutic ability for treatment of metabolic syndrome-comorbidities. Additionally, self-assembly peptides combine safety, tolerability, and effectivity attributes; by this presenting a promising platform for the development of novel pharmaceuticals capable of addressing unmet therapeutic needs for diabetes, cardiovascular disorders and obesity. In this review, recent advances in developing self-assembly peptide nanostructures tailored for improving treatment of metabolic syndrome and related diseases will be discussed from basic research to preclinical research studies. Challenges facing the development of approved medicinal products based on self-assembling peptide nanomaterials will be discussed in light of regulatory requirement for clinical authorization.
\end{abstract}

Keywords: peptide, hydrogel, nanomaterials, metabolic syndrome, diabetes, obesity, cardiovascular disease

\section{Introduction}

Metabolic syndrome (MS) comprises a cluster of metabolic abnormalities, such as accumulation of lipids, insulin resistance, and chronic inflammation, which ultimately lead to three main long-term medical conditions, type 2 diabetes, cardiovascular diseases (CVDs), and ischemic stroke. ${ }^{1}$

According to the World Health Organization, alarmingly there is about 422 million diabetics worldwide, which have been mainly diagnosed in developing countries. ${ }^{2}$ Moreover, CVDs represent the first cause of death globally, where $85 \%$ of CVD deaths are caused by heart attacks and strokes. ${ }^{3}$ With regard to obesity, in countries such as
Correspondence: Luis Alberto Castillo-

Díaz

Department of Medicine and Health

Sciences, University of Sonora,

Hermosillo, Sonora 83000, Mexico

Tel +52 6622592 I2l Ext. 4593

Email luis.castillo@unison.mx
International Journal of Nanomedicine 2020:15 10349-10370

10349

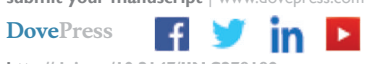

http://doi.org/10.2147/1IN.S278189 
Australia, Chile, Canada, South Africa, and the United Kingdom, more than one in four adults are obese, while the United States of America and Mexico, are the countries with more cases of diagnosed obesity in the Americas. ${ }^{4}$

The current management to address MS-related metabolic abnormalities includes adopting a healthy lifestyle and following a long-term medication regimen. ${ }^{1}$ However, such a strategy is difficult to accomplish for patients, since various drugs are prescribed for only one pathology and this is expensive. ${ }^{5}$ In this context, the development of drugs containing more than one bioactive agent, which is known as the "polypill-based approach", reduces costs, when generic bioactive agents are used. Nonetheless, research is still ongoing in order to overcome the risks of side effects related to such a polypill therapy. ${ }^{5,6}$

In recent years, medicine has benefitted from the technological advances of tissue engineering and regenerative medicine. Within such a technology, advanced peptide-based nanomaterials formed from the self-assembly of amino acids have regained considerable attention for the treatment of chronic diseases. This can be possible thanks to the inherent physicochemical characteristics of amino acids, which act as building blocks to form more complex nanofibrillar formulations exhibiting high versatility and reproducibility. ${ }^{7,8}$ The fine-tuning of supramolecular interactions held among peptides triggers either their assembly or disassembly through direct interactions, peptide conjugations or synthesis strategies. This approach relies on non-covalent interactions, such as hydrogen bonding, electrostatic, hydrophilic and hydrophobic, van der Walls, and pi-stacking. Thus, naturally occurring, secondary structures, such as $\beta$-sheet, $\beta$-turns, random coils, and $\alpha$-helix, ultimately lead to the formation of nanostructured fibers, fibrils, micelles, ribbons, tapes, etcetera. ${ }^{9,10}$ Peptide assembly and disassembly are held under specific conditions and well-controlled conditions, which include enzymatic conjugation, ${ }^{11} \mathrm{pH},{ }^{12}$ or ionic strength responsiveness, ${ }^{13}$ all of them offering significantly advantages for biomedical applications. ${ }^{14}$

Therefore, from a wide library of amino acids and their equally possible combinations, various peptides can be formulated to design peptide-based nanostructures, such as dimensional (3D) hydrogels, solutions, and other matrices as pharmaceuticals with significant potential to tackle metabolic syndrome and its related comorbidities. ${ }^{7}$

Since their serendipitously discovery in 1990, self-assembling peptide hydrogels (SAPHs) are ubiquitous in medicinal chemistry and for more than twenty years, they have extended their biomedical applications. Studies have focused to design
SAPHs to act as three-dimensional (3D) matrices for the encapsulation of mature ${ }^{15-17}$ and stem cells, ${ }^{18-20}$ as well as to deliver biological entities, such as growth factors and drugs in a sustained and controlled manner. Other applications for SAPHs include, bioprinting for tissue engineering, stabilization of membrane proteins (G-protein), and more recently, some SAPHs have reached clinical trials to help wound healing. ${ }^{21}$

With respect to metabolic syndrome, the design of selfassembling peptides is being exploited for the development of advanced 3D gels that, when combined with key biomolecules ${ }^{7,22,23}$ or cells, ${ }^{24}$ represent a promising alternative to regenerate damaged tissues of patients undergoing hyperglycemia, CVDs, and other related, since the predictable metabolism along with reproducible protocols to form such scaffoldings is being increasingly refined. Furthermore, peptide-based formulations, such as matrices or solutions are being designed to develop novel pharmaceutics with increased efficacy, safety, and tolerability for treating hyperglycemia ${ }^{25}$ and obesity. ${ }^{26}$ In this review, the potential and current limitations related to peptide-based formulations to address metabolic syndrome and related chronic diseases are concisely provided and discussed.

\section{Metabolic Syndrome (MS), An Overview}

MS is a medical condition characterized by abdominal obesity, insulin resistance, hypertension, and hyperlipidemia, which alarmingly has become the main non-communicable disease health hazard worldwide. ${ }^{1,27}$ Type 2 diabetes, coronary pathologies, and stroke represent the major diseases derived from MS. Overall, the etiology of this hazardous syndrome consist on long term industrialized food consumption, which is characterized by a high caloric and low fiber element, as well as prolonged physical sedentarism. ${ }^{27}$

According to the National Cholesterol Education Program Adult Treatment Panel III, three or more of the criteria listed in Table 1 are required for MS diagnose. ${ }^{28,29}$ However, it also has to be noted that the criteria to diagnose MS may vary depending on the age, gender, and ethnic origin of the subjects. The pathophysiology of MS is complex and is highly dependent on the gradual distortion of metabolic homeostasis, which ultimately leads to the impairment of the physiological functions of several organs and tissues. The reader is referred to The metabolic syndrome (chapter 3 ), for a deeper understanding in this matter. ${ }^{30}$ 
Table I Representative of Diagnosis Criteria for Metabolic Syndrome

\begin{tabular}{|l|l|l|}
\hline Comorbidity & Diagnosis & Ref. \\
\hline Central obesity & Waist circumference $>102 \mathrm{~cm}$ (males) or $>88 \mathrm{~cm}$ (females). & 31 \\
Lipid profile & Triglycerides $\geq 150 \mathrm{mg} / \mathrm{dl}^{31}$ & 31 \\
& HDL-cholesterol $<40 \mathrm{mg} / \mathrm{dl}$ (males) or $<50 \mathrm{mg} / \mathrm{dl}$ (females). \\
Blood pressure & $\geq 130 / 85 \mathrm{~mm} \mathrm{Hg.}$ & 31 \\
Hyperglycemia & Fasting glucose $\geq 110 \mathrm{mg} / \mathrm{dl}$ (modified to $>100 \mathrm{~g} / \mathrm{dl}$ (diabetes). \\
\hline
\end{tabular}

In 2016, 17.9 million people died from CVDs, and $85 \%$ from such deaths were due to heart attack, and stroke. Likewise, more than $75 \%$ of CVD deaths occur in lowincome and mild-income countries. ${ }^{3}$ In the same year, diabetes mellitus (DM) caused the death of about 1.6 million subjects, which placed this pathology as the seventh leading cause of death globally. ${ }^{2}$ In the European region about 60 million people have been diagnosed with diabetes and such an epidemiologic profile continues to increase among all ages each year. ${ }^{32}$ In the Americas, the epidemiologic profile is even less encouraging, since in the United States of America, about 71,000 people died from diabetes in the same year, ${ }^{33}$ while in Mexico, 87,000 deaths were recorded. ${ }^{34}$

Medical associations worldwide recommend changes of lifestyle, which include a reduction of caloric intake, increasing physical activity, and encouraging weight loss as a first alternative for MS treatment. In addition, before any pharmacological prescription, MS treatment recommendations include monitoring full lipid and thyroid hormones, as well as exploring liver function and urine albumin to discard further metabolic abnormalities. ${ }^{1,29}$ (Table 2). Unfortunately, such management is not completely effective for all patients. ${ }^{29}$

Table 2 Representative of the Gold Standard for the Treatment of Metabolic Syndrome

\begin{tabular}{|c|c|c|}
\hline Risk Factor & Strategies & Ref. \\
\hline Abdominal obesity & $\begin{array}{l}\text { First year: reduction of body weight } 7 \%-10 \% \text {. } \\
\text { Weight loss with a final BMI goal }<25 \mathrm{~kg} / \mathrm{m}^{2} \text {. }\end{array}$ & 35,36 \\
\hline Physical Inactivity & Carry out continuous physical activity (ca. $30 \mathrm{~min}$ ) or at moderate intensity ( 5 times a week). & $35,37,38$ \\
\hline Diet & $\begin{array}{l}\text { Reduction intake of saturated fat, trans fat, and cholesterol. } \\
\text { Follow Mediterranean diet. } \\
\text { Follow DASH. } \\
\text { Lowering carbohydrates index. } \\
\text { High fiber diet }>30 \mathrm{~g} / \text { day. }\end{array}$ & $35,37,39,40$ \\
\hline $\begin{array}{l}\text { Dyslipidemia. } \\
\text { High LDL cholesterol. } \\
\text { High non-HDL cholesterol. } \\
\text { Reduced HDL cholesterol. }\end{array}$ & $\begin{array}{l}\text { Lowering LDL cholesterol }<130 \mathrm{mg} / \mathrm{dl} \text { or } \\
<100 \mathrm{mg} / \mathrm{dl} \text {, and }<70 \mathrm{mg} / \mathrm{dl} \text { for high and very high risk, repectively. } \\
\text { Triglycerides } \geq 200 \mathrm{mg} / \mathrm{dl} \text {, non-HDL cholesterol is a second goal. } \\
\text { Increase of HDL cholesterol as a third goal (at non-specified values). } \\
\text { Statin-based treatment. }\end{array}$ & $36,38,39,41$ \\
\hline High blood pressure & Antihypertensive drugs must be introduced even at lower blood pressures $(<140 / 90)$. & $36,38,42,43$ \\
\hline High glucose & $\begin{array}{l}\text { For IFG, encourage weight reduction and physical activity. } \\
\text { Metformin and other oral hypoglycemic agents. } \\
\text { Achieve glycosylated hemoglobin to } 7 \% \text { or less. }\end{array}$ & $36,38,43$ \\
\hline Prothrombotic state & Low-dose acetylsalicylic acid for high-risk patients. & 36 \\
\hline Proinflammatory state & Lifestyle therapies. & 36 \\
\hline Habits & Avoid smoking and alcohol. & 35,38 \\
\hline
\end{tabular}

Abbreviations: LDL, low-density lipoprotein; HDL, high-density lipoprotein; DM, diabetes mellitus; IFG, impaired fasting glycaemia; DASH diet, dietary approaches to stop hypertension; BMI, body mass index. 
Therefore, the prescription of pharmacological therapy under medical supervision is needed. The standard pharmacotherapy for MS treatment and related comorbidities includes hypoglycemic, antihypertensive, and anticholesteremic drugs (Table 3$)^{1}{ }^{1}$

However, such a drug management faces various limitations. Firstly, drug regimens are often difficult to be accomplished for patients, since separate drugs are prescribed for only one MS-related medical condition. This also complicates medical monitoring by practitioners. Secondly, the prescription of various drugs increases the risk of pharmacological secondary effects. Lastly but not least, such pharmacological regimen is highly expensive. ${ }^{5}$ Overall, this scenario causes scientists to seek new strategies to overcome the current limitations of MS management, where self-assembled peptides have reemerged as a promising route for patients undergoing MS.

\section{Design Approaches of Self-Assembling Peptide Nanostructures and Hydrogels for MS Applications}

A bottom-up design approach has been adopted by biomaterials engineers for the development of self-assembling peptide-based nanostructures. This approach involves using a chemical toolbox of amino acid building blocks for the rational design of a peptide primary sequence, which is purposely developed to adopt a bioinspired secondary structure capable of self-assembly into higher nanostructures (Figure 1A). Self-assembly occurs via non-covalent interactions between peptide chains involving hydrogen bonding between peptide backbone amides, as well as between sidechains, Van der Waals, hydrophobic interactions, pi-stacking between aromatic residues, and electrostatic interactions between charged residues. ${ }^{9,10}$ For instance, peptides designed to acquire $\alpha$-helical structures via inter-chain hydrogen bonding and self-organize/co-organize into coiled-coil structures via hydrophobic and electrostatic attraction, forming nanotubes as well as rigid extended nanofibers (Figure 1B). ${ }^{46-50} \mathrm{In}$ contrast, $\beta$-sheet forming peptides are typically ionic-complementary sequences inspired from the unusual sequence pattern of the baker's yeast Zuotin protein domain, ${ }^{51-53}$ which were designed to self-assemble via backbone amide interchain interactions forming extended, but more flexible, $\beta$ sheet nanofibers that entangle to form hydrogels at a relevant critical gelation concentration (Figure 1C). ${ }^{54-58}$ Similarly, $\beta$ hairpin forming peptides are longer sequences designed with "kink-forming" residues in the middle, usually prolines, which upon bending can self-assemble via intra-chain hydrogen bonding between peptide backbone amides and lateral association of hairpins into $\beta$-sheet like nanofibrous structures forming hydrogels (Figure 1D). ${ }^{59-61}$ Self-assembling short aromatic peptides were designed inspired by amyloid peptides with diphenyl alanine (FF) in the sequence core, which are believed to drive self-assembly through aromatic pistacking. ${ }^{62}$ Short aromatic peptide sequences are, thus, either formed of aromatic residues or capped with aromatic protecting groups, such as fluorenylmethoxycarbonyl (Fmoc), carboxybenzyl (CBZ), or naphthyl (Naph) groups, to facilitate self-assembly through pi-stacking into nanofibers capable of hydrogelation (Figure 1E) ${ }^{63-65}$ Single amino acids capped with aromatic protecting groups also showed to self-assemble into nanofibrous structures forming hydrogels. ${ }^{66-68}$ Amphiphilic peptides, contrarily, are surfactant-like structures with a hydrophilic peptide sequences capped with long hydrophobic hydrocarbon chains that are capable of self-assembly into micellar cylinders forming nanofibrous hydrogels in aqueous media (Figure 1F). ${ }^{69-71}$ Amphiphilic block copolypeptide designs have also shown hydrogelation capacity. ${ }^{72-74}$ Self-assembly could be triggered for these de novo peptides by manipulating the external environment conditions, which could be thermal, ${ }^{58,75,76}$ photo, ${ }^{77-79}$ or enzymatic triggers,$11,80-82$ as well as dramatic changes in $\mathrm{pH},{ }^{54,83}$ and ionic strength. ${ }^{60,84,85}$

Self-assembling peptide nanostructures and hydrogels have a great potential for therapeutic, pharmaceutical and biomedical applications, thanks to the versatility of the designs as discussed above, the ease of synthesis and chemical functionalization, physicochemical tunability, biocompatibility and biodegradability. In addition, these are in most cases viscoelastic shear thinning and thixotropic soft materials, implying injectability and sprayability. By virtue of these attributes, peptide hydrogels have been used as therapeutic materials, and cellular scaffolds as potential treatment strategies for medical conditions associated with metabolic disorders. As therapeutic materials, the self-assembling peptide sequence itself possesses pharmacological activity. Peptide hydrogels have also been widely used as delivery vehicles for a wide variety of drug treatments for metabolic conditions, which can act as drug depot formulations ${ }^{22,86-91}$ for stabilizing and delivering drug molecules vulnerable to metabolic degradation, such as the anti-diabetic drugs DPPIV inhibitor sitagliptin, ${ }^{87}$ and insulin. ${ }^{86,88}$ The stabilization capacity of such hydrogels also made them optimal vehicles for the delivery of growth factor proteins for tissue regeneration and repair in $\mathrm{CVDs},{ }^{91-93}$ and for facilitating 
Table 3 Representative of the Pharmacological Therapy for Metabolic Syndrome

\begin{tabular}{|c|c|c|c|}
\hline Comorbidity & Drugs & Mechanism of Action & Ref. \\
\hline Obesity & $\begin{array}{l}\text { Lipase inhibitor. } \\
\text { Orlistat. }\end{array}$ & $\begin{array}{l}\text { Inhibit gastric and pancreatic lipases, which leads to breakdown dietary fat. } \\
\text { The administration of orlistat decreases fat absorption ca. } 30 \% \text {. }\end{array}$ & 44 \\
\hline \multirow[t]{4}{*}{ Dyslipidemia } & $\begin{array}{l}\text { HMG-CoA reductase inhibitors (Statins). } \\
\text { Atorvastatin, Lovastatin, Simvastatin, } \\
\text { Rosuvastatin, Pravastatin, Ezetimibe. }\end{array}$ & $\begin{array}{l}\text { Inhibit HMG CoA reductase to limit intracellular cholesterol synthesis. } \\
\text { Statins also increase the number of cell surface LDL receptors that bind and } \\
\text { internalize circulating LDLs, which reduces plasma cholesterol levels. }\end{array}$ & 44 \\
\hline & $\begin{array}{l}\text { Fibrates. } \\
\text { Gemfibrozil, Fenofibrate, Bezafibrate. }\end{array}$ & $\begin{array}{l}\text { Activate PPARs to decrease triglyceride concentrations through a dual } \\
\text { response, increasing the expression of lipoprotein lipase and decreasing the } \\
\text { concentration of apolipoprotein (apo) Cll. }\end{array}$ & 44 \\
\hline & $\begin{array}{l}\text { Nicotinic. } \\
\text { Niacin, Niaspan. }\end{array}$ & $\begin{array}{l}\text { Inhibit lipolysis in adipose tissue, through the reduction of the production of } \\
\text { free fatty acids. The reduction of liver triglyceride levels decreases hepatic } \\
\text { VLDL production, which in turn reduces LDL-C plasma concentrations. }\end{array}$ & 44 \\
\hline & PCSK9 inhibitors. & $\begin{array}{l}\text { Since PCSK9 is involved in the degradation of LDL receptors in the liver, } \\
\text { blocking its activity with monoclonal antibodies reduces the degradation of } \\
\text { LDL receptors and increases the clearance of LDL cholesterol for several } \\
\text { weeks. }\end{array}$ & 45 \\
\hline \multirow[t]{2}{*}{ Diabetes } & $\begin{array}{l}\text { Biguanides. } \\
\text { Metformin. }\end{array}$ & $\begin{array}{l}\text { Reduce hepatic gluconeogenesis and slow the intestinal absorption of } \\
\text { carbohydrates; improvement of peripheral glucose uptake and utilization. }\end{array}$ & 44 \\
\hline & $\begin{array}{l}\text { Thiazolidinediones (TZDs). } \\
\text { Rosiglitazone, Pioglitazone. }\end{array}$ & $\begin{array}{l}\text { Agonist effect on PPAR } \gamma \text {, which leads to lowering insulin resistance. This } \\
\text { results in an increased insulin sensitivity in various tissues, such as the } \\
\text { adipose tissue, liver, and skeletal muscle. }\end{array}$ & 44 \\
\hline Hypertension & $\begin{array}{l}\text { Angiotensin-converting enzyme (ACE } \\
\text { inhibitor). } \\
\text { Captopril, Enalapril, Ramipril, Quinapril, } \\
\text { Lisinopril, Fosinopril. }\end{array}$ & $\begin{array}{l}\text { Lower blood pressure through the reduction of peripheral vascular } \\
\text { resistance, which increases cardiac output, heart rate, and contractility. } \\
\text { Likewise, block the enzyme ACE, which cleaves angiotensin I to form the } \\
\text { potent vasoconstrictor angiotensin II. }\end{array}$ & 44 \\
\hline \multirow[t]{4}{*}{$\begin{array}{l}\text { Prothrombotic } \\
\text { state }\end{array}$} & $\begin{array}{l}\text { Angiotensin II receptor blockers (ARBS). } \\
\text { Losartan, Valsartan, Irbesartan, } \\
\text { Candesartan, Telmisartan, Eprosartan, } \\
\text { Olmesartan }\end{array}$ & $\begin{array}{l}\text { ARBS exert an antagonist action on ATI receptors leading to the } \\
\text { impariment of several angiotensin II effects, such as vasoconstriction. Thus, } \\
\text { ARBS produce arteriolar and venous dilation, as well as inhibit aldosterone } \\
\text { secretion, which ultimately decreases blood pressure, as well as salt and } \\
\text { water retention. }\end{array}$ & 44 \\
\hline & $\begin{array}{l}\text { Calcium channel blockers. } \\
\text { Amlodipine, Diltiazem, Verapamil, } \\
\text { Dihydropyridine. }\end{array}$ & $\begin{array}{l}\text { Impair inward internalization of calcium into cells once bind to L-type calcium } \\
\text { channels in the heart and in smooth muscle of the coronary and peripheral } \\
\text { arteriolar vasculature. This causes vascular smooth muscle relaxation, and } \\
\text { dilatation of arterioles. Calcium channel blockers do not dilate veins. }\end{array}$ & 44 \\
\hline & $\begin{array}{l}\text { Thiazide diuretics. } \\
\text { Chloratanidone. }\end{array}$ & $\begin{array}{l}\text { Decrease the reabsorption of } \mathrm{Na}^{+} \text {on the cortical region of the ascending } \\
\text { loop of Henle and the distal convoluted tubule. It is believed that Thiazides } \\
\text { inhibit the } \mathrm{Na}^{+} / \mathrm{Cl}^{-} \text {cotransporter on the luminal membrane of the renal } \\
\text { tubules (having a lesser effect in the proximal tubules). Thiazides increase } \\
\text { the concentration of } \mathrm{Na}^{+} \text {and } \mathrm{Cl}^{-} \text {in the tubular fluid. }\end{array}$ & 44 \\
\hline & $\begin{array}{l}\text { Acetylsalicylic acid. } \\
\text { Aspirin. }\end{array}$ & $\begin{array}{l}\text { Inhibit thromboxane } \mathrm{A} 2 \text { synthesis through the acetylation of a serine } \\
\text { residue on the active site of COX-I, which irreversibly inactivates such an } \\
\text { enzyme. This favors the anti-aggregation effects of prostacyclin, preventing } \\
\text { platelet aggregation. }\end{array}$ & 44 \\
\hline
\end{tabular}

Abbreviations: ATI, angiotensin type I; COX-I, cyclooxygenase-I; HMG-Co-A, 3-hydroxy-3-methyl-glutharyl-coenzyme A reductase; LDL, low-density lipoprotein; LDLC, low-density lipoprotein cholesterol; PPARs, peroxisome proliferator-activated receptors; PPAR $\gamma$, peroxisome proliferator-activated receptor gamma. 


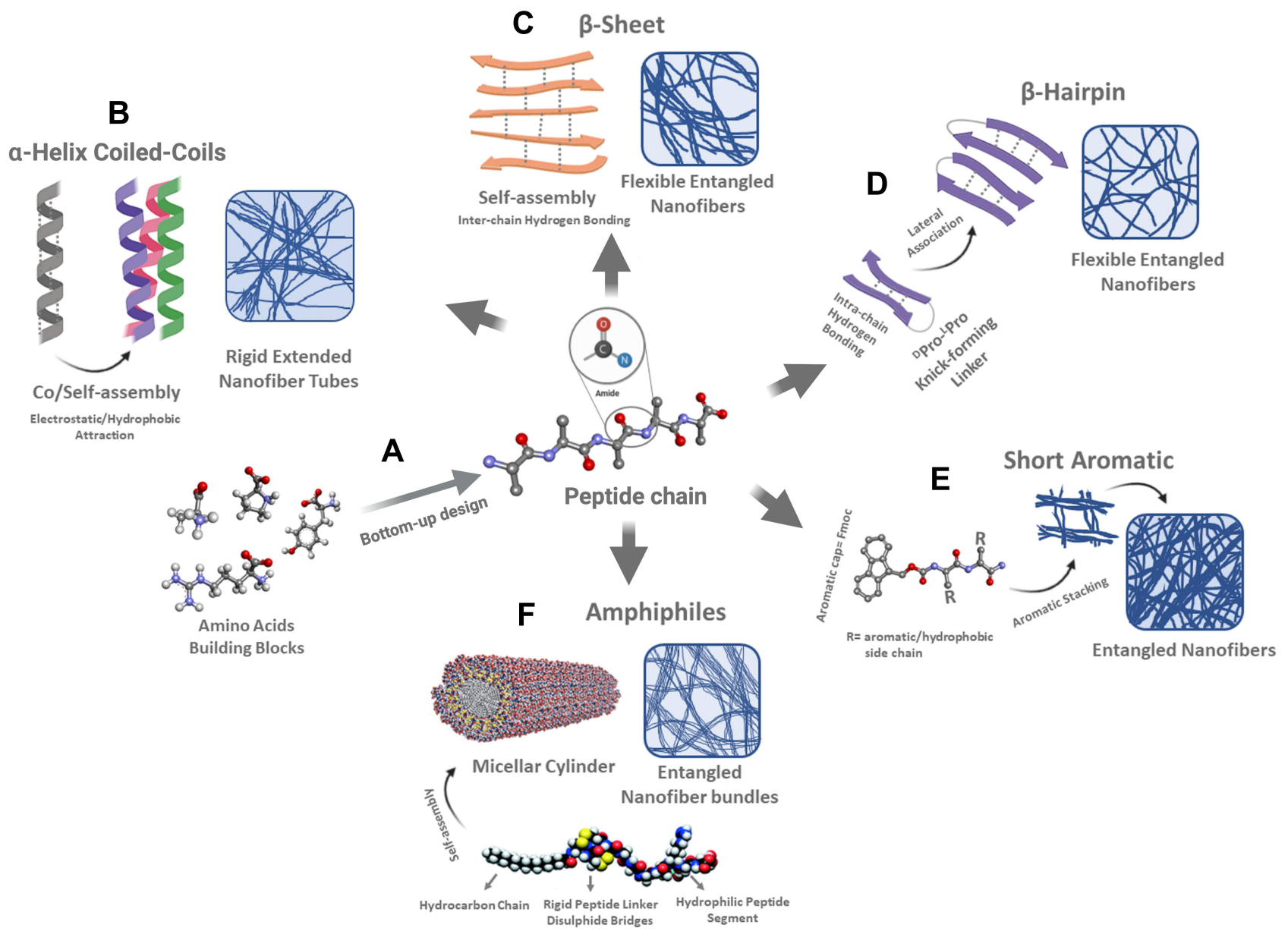

Figure I Depiction of bottom-up design approach for de novo peptides capable of self/co-assembly into different classes of bioinspired nanofibrous structures. (A) Amino acids acting as building blocks form hierarchical structures, such as (B) $\alpha$-helix (C) $\beta$-sheet, (D) $\beta$-hairpin, (E) short aromatic, and (F) amphiphile peptides. Dashed lines denote hydrogen bonds.

Note: Micellar Cylinder and Amphiphile Structure taken from Hartgerink JD, Beniash E, Stupp SI. Self-assembly and mineralization of peptide-amphiphile nanofibers. Science. 2001;294,(5547):1684-1688. doi:10.1 126/science.1063187. Reprinted and modified with permission from AAAS. ${ }^{72}$

transplantation of pancreatic islets as a new treatment strategy for diabetes. ${ }^{17,94-98}$

Despite the significant research efforts in the development of peptide-based biomaterials for a variety of biomedical applications, only a few studies have focused on the development of such materials for the treatment metabolic syndrome-associated factors (MSAFs), such as hyperglycemia, hypertension, hypercholesteremia, as well as for tackling long-term pathologies derived from MS. In the next sections, such research, will be presented. ${ }^{86,99}$

\section{Acellular Self-Assembled Peptide Hydrogels for the Treatment of Hyperglycemia}

The self-assembly of peptides represents a straightforward and cost-effective approach to form biocompatible hydrogels through a minimalist Fmoc chemistry focused on overcoming hyperglycemia. Peptide systems have been synthesized to form self-supported SAPHs with remarkable diffusion, mechanics, and nanofibrillar architecture highly suitable for biomedical applications. Thus, one of the most remarkable approaches to address either type I (TIDM) or type II diabetes mellitus (TIIDM) is exploiting the assembly and disassociation of peptides to form hydrogels capable of encapsulating and delivering various types of proteins, drugs, and cells to drive biological responsiveness. Moreover, recent studies explore the rationale stabilization of peptide-based formulations to develop novel antidiabetic pharmaceutics with desirable pharmacodynamic and pharmacokinetic profiles. ${ }^{100,101}$

The fine-tuning of peptide $\mathrm{pH}$-responsiveness within peptide formulations is an alternative to meet hyperglycemia. An example of this is the glucose responsive $\beta$-sheet-based peptide hydrogel RATEA-16 also known as F0 hydrogel, which has shown a good potential to release bovine insulin 
(Figure 2). In order to facilitate the encapsulation of insulin and the subsequent peptide hydrogel disassembly, alanine residues were substituted by valine and isoleucine throughout the peptide backbone. Both, valine and isoleucine are known to display more hydrophobic forces. In addition, arginine was substituted by ornithine to favor the disassembly of the RATEA-16 hydrogel. The disassembling of the peptide hydrogel is driven by electrostatic repulsions held between ornithine residues at low $\mathrm{pH}$ conditions, as a result of the activity of both catalase and glucose oxidase $(\mathrm{GO})$, which convert glucose into gluconic acid (Figure 2A1). Such a continuous release of insulin is held at a glucose concentration-dependent manner to restore euglycemia in vitro and in vivo over $12 \mathrm{~h}$ with no signs of toxicity (Figure 2A2 and A3).

The human oxyntomodulin (Oxm) peptide, which is a 37-amino acid proglucagon derived peptide with high homology to both glucagon and glucagon-like peptide 1 (GLP-1), is capable of self-assembling into a nanofibrillar hydrogel-like conformation. The self-assembly of Oxm gels takes place under ionic strength, well-controlled physiological $\mathrm{pH}$ conditions, and following one-step dilution with Oxm peptide solution (non-fibrillar Oxm). Interestingly, Oxm hydrogels succeeded to boost an agonist effect on $\mathrm{CHO}$ cells genetically engineered to express both human glucagon and GLP-1 receptors. After a single subcutaneous injection with Oxm gels, cAMP significantly increased and circulating glucose levels dropped in wildtype mice over $5 \mathrm{~h}$, as recorded by tolerance glucose assays. According to the authors, such an encouraging outcome might be facilitated by the progressive disassociation of Oxm gels, which ultimately led to the slow release of monomeric entities exhibiting a larger bioactivity in comparison to the treatment with the non-fibrillar Oxm peptide formulation at the same dosage. Thus, Oxm gels represent a promising route to develop novel drugs, capable of assembling and dissociate under mild conditions to restore euglycemia with a prolonged lifespan in comparison to hypoglycemic pharmaceuticals. However, exploring the role of $\mathrm{Oxm}$ for anti-obesity therapeutics remains on the lookout for further research. ${ }^{25}$

The incorporation of whole proteins within SAPHs is another widely used approach for biomedical applications. Incretins, such as glucagon like peptide-1 (GLP-1) play a critical role promoting the release of insulin following meal intake. Nevertheless, such proteins are rapidly inactivated (ca. 2-3 $\mathrm{min}$ ) by the gastrointestinal enzyme dipeptidyl peptidase-4 (DPP-IV), whose high expression can lead to the development of TIIDM. In order to target such metabolic imbalance, the capability of RADA16-II gels to encapsulate hempseed protein hydrolysates (food protein hydrolysates) and sitagliptin (an oral hypoglycemic DPP-IV inhibitor) both known to offer hypoglycemic activity was assessed. When RADA16-II encapsulating both hypoglycemic biologics was transferred in situ and ex vivo (Caco-2 cells and human serum, respectively), a synergic drug effect was achieved, since a significant reduction on the activity of DPP-IV was recorded at reduced dosage of sitagliptin over 10 minutes, showing the capability of RADA16-II to protect the hypoglicemiant molecules from degradation with no signs of toxicity. Considering that GLP-1 has a very short lifespan under physiological conditions, the results derived from this research make RADA16-II an attractive scaffold to extend and optimize the effectivity of hypoglycemic entities. ${ }^{87}$

RADA-16-II peptide gel was the first ionic-complementary SAPH discovered in the field, which is currently commercialized as PuraMatrix ${ }^{\mathrm{TM}}$. RADA16-II is formed from the self-assembling of $\beta$-sheet forming peptide Ac$(\mathrm{RADA})_{4}-\mathrm{CONH}_{2}$, which upon subcutaneous injection undergoes sol-to-gel transition forming a stable nanofibrous hydrogel depot formulation. Nowadays, one of the most recent biomedical applications of RADA16-II includes supporting the encapsulation of antidiabetic biologics to restore the function of pancreatic tissue and cells. $^{21,87}$ Yoon et al used RADA16-II as a biological vehicle to encapsulate the synthetic immunostimulatory oligonucleotide CpGODN1826 (CpG), granulocyte macrophage colony-stimulating factor (GM-CSF), and poly (lactide-co-glycolide) (PLGA) microparticles containing human insulin. The peptide hydrogel formulation boosted the production of IL-10, which according to the authors, led to an immune tolerance-like effect that ultimately restored euglycemia and prevented the development of TIDM in vivo. It is believed that both $\mathrm{CpG}$ and GM-CSF in RADA16-II gels played a key role as adjuvants to trigger the production of IL-10. This research clearly highlights the versatility of SAPHs as alternative biologics for the development of novel antidiabetic vaccines. ${ }^{99}$

\section{Cell-Load Self-Assembled Peptide Hydrogels for the Treating Hyperglycemia}

Although hyperglycemia derived from TIDM is not directly related to MS, it is worth to address the state of the art of SAPHs applications in this matter. More than 20 
A

A1)

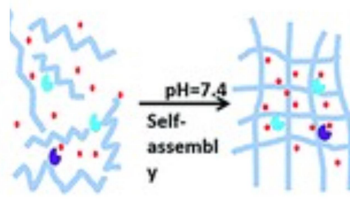

- Insulin G gox 6 caT

- Glucose - Gluconic Acid

A2)

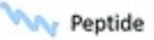

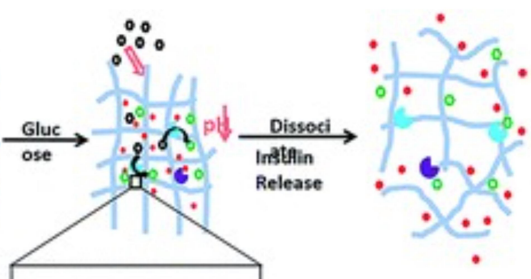
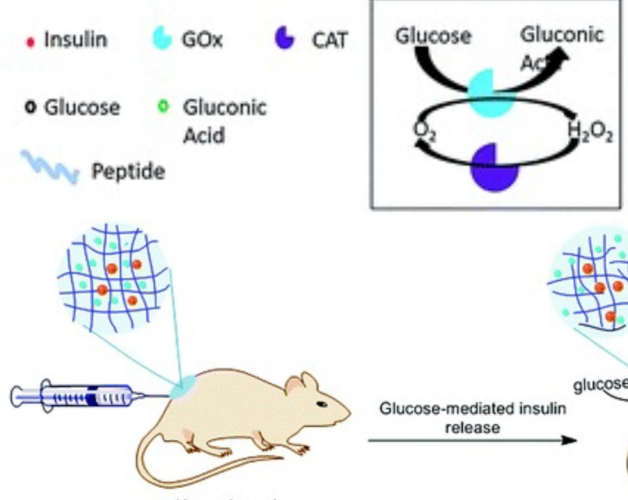

Hyperglycemia
Euglycemia

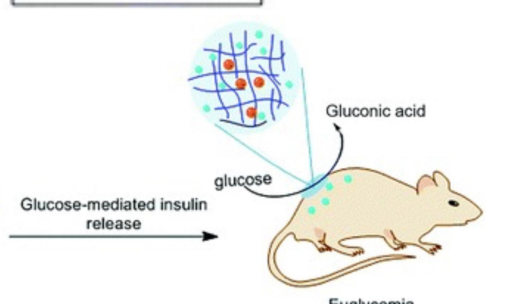

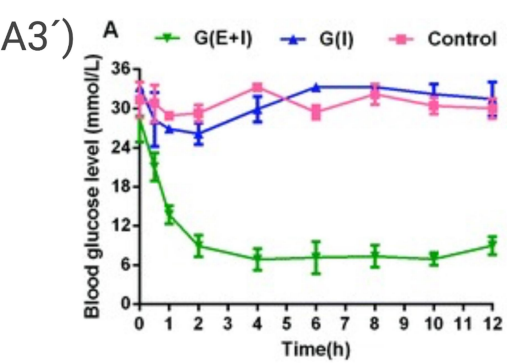

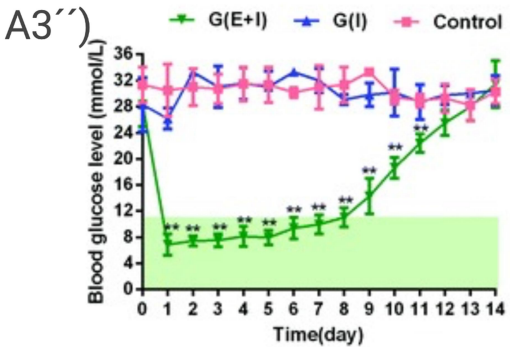

B
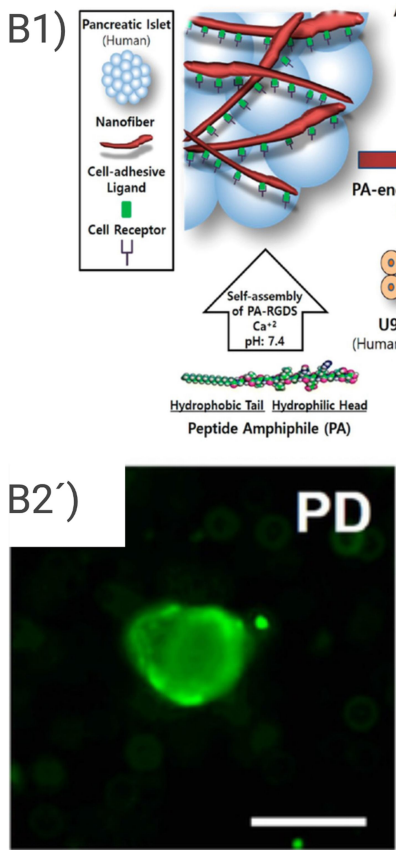

$\begin{array}{cc}\text { Allow Diffusion of Glucose, } & \text { Prevent Contact with } \\ \text { Oxygen, and Nutrients. } & \text { Immune Cells }\end{array}$
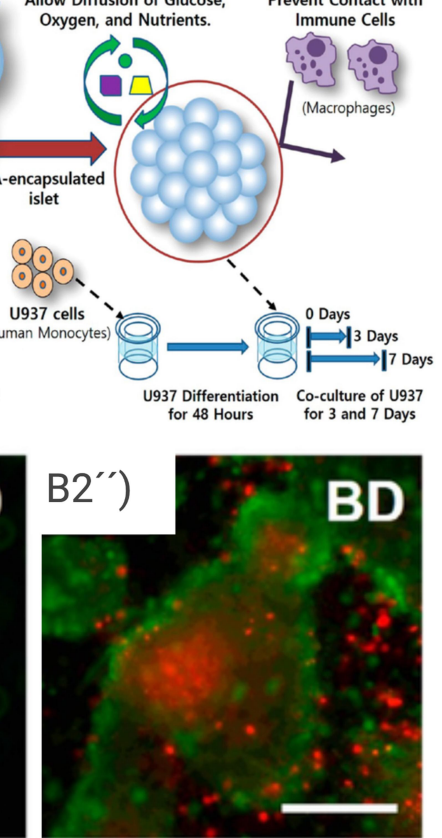

B3)

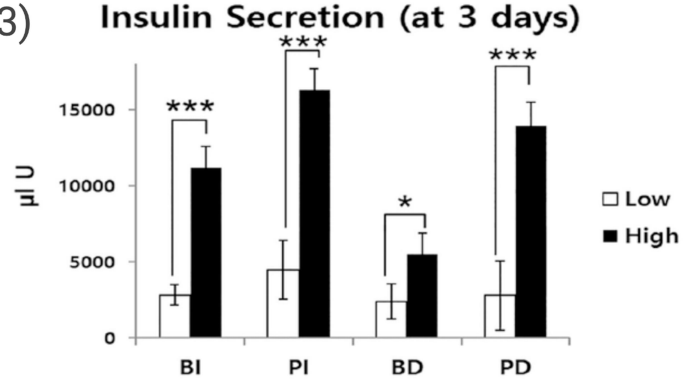

Insulin Secretion (at 7 days)

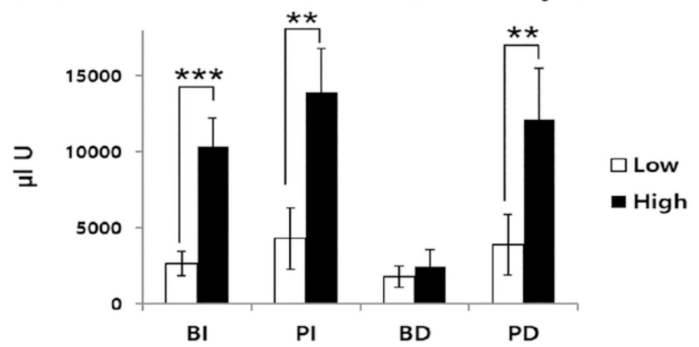

Figure 2 Representative of both (A) acellular and (B) cellular peptide-based hydrogel approaches to tackle hyperglycemia. (AI) Glucose-responsive peptide hydrogel encapsulating insulin and enzymes is $\mathrm{A} 2$ ) transferred into diabetic animals $\mathrm{A} 3^{\prime}$ ) to reduce the levels of glucose and A3') maintaining normoglycemia up to 8 days. I = insulin, $\mathrm{E}=$ enzymes. $\mathrm{BI}$ ) Nanomatrix gel encapsulating human islets and inflammatory cells, B2') supports de viability of human islets (green fluorescent color) under an inflammatory environment in comparison to B2") bare islets, whose viability is impaired (red fluorescent color) over 7 days of culture. B3) Insulin secretion by human islets cultured inside Nanomatrix is higher in comparison to bare islets without Nanomatrix under an inflammatory environment at days 3 and 7. PD $=$ human islets cocultured with inflammatory cells in Nanomatrix, BD $=$ bare islets cocultured with inflammatory cells, $\mathrm{BI}=$ bare islets, $\mathrm{PI}=$ islets encapsulated in Nanomatrix. Scale bar $=200 \mu \mathrm{m}$. Figure $2 \mathrm{~A}$ was adapted with permission from Inyectable self-assembled peptide hydrogels for glucose mediated insulin delivery. M. Fu, Ch. Zhang, Y, Dai, X, Li, M, Pan, W, Huang, H, Qian and L. Ge. Biomaterials Science 6 (6), I480-149I, 2018. https://pubmed.ncbi.nlm.nih.gov/ 29623975/. The Royal Society of Chemistry. ${ }^{88}$ Figure 2B Copyright @2017. American Chemical Society. Adapted from Hwang PTJ, Shah DK, Garcia JA, et al. Encapsulation of human islets using a biomimetic self-assembled nanomatrix gel for protection against cellular inflammatory responses. ACS Biomater Sci Eng. 20I7;3(9):21I0-2II9. doi:10.102I/ acsbiomaterials.7b0026I. ${ }^{108}$ 
years have passed, since intraportal islet transplantation (Edmonton's protocol) was established as an encouraging approach to meet TIDM. However, such a therapy very often fails due to the poor retention and low viability of islets once grafted into the affected tissue. Three major facts cause the failing of islet transplantation, which include an exacerbated inflammatory process, oxidative stress, and autoimmune reactions. ${ }^{102}$ Today, both synthetic and naturally derived hydrogels are developed to provide protection to pancreatic cells from harsh environments after transfer in vivo and in situ. Overall, these biomaterials have achieved remarkable outcomes to potentially improve insulin independence in diabetics. ${ }^{103-106}$

Within peptide formulations, one major successfully approach is functionalizing peptide gels with extracellular matrix moieties, such as RGD (fibronectin), YIGSR (laminin), and LRKKLGKA (vascular endothelial growth factor [VEGF]), to provide them with key biological signals to direct cellular functions in a well-controlled manner in comparison to other naturally-derived formulations. ${ }^{89}$

Within the family of self-assembling peptides, amphiphilic peptides formed by a hydrophobic alkyl tail, a hydrogen-bonding peptide, and a charged hydrophilic head have achieved encouraging outcomes. Such is the case of the alkylated PA Nanomatrix (GTAGLIGQRGDS), which has shown to be suitable to support the culture and function of human islets over 7 days in vitro, as islets could be protected from inflammatory environments derived from differentiated monocytes. Moreover, human islets maintained insulin production within gel after high glucose stimulation in comparison to non-encapsulated cells (Figure 2B). This encouraging outcome could be facilitated by RGD, which was exposed throughout the nanofibrillar architecture of gels. ${ }^{107}$ This result is in good agreement with previous research showing the key role that RGD-functionalized Nanomatrix had in improving the biological functions of murine insulin-producing cells in vitro. ${ }^{108}$

Another approach evaluated the positive effect that nitric oxide (NO) had on the viability and functions of murine $\beta$-cells after being released from Nanomatrix. Therefore, this hydrogel was designed from two functionalized peptides, the first one linking YIGSR and the second one offering a polylysine NO donor linked to a metalloproteinase-2 (MPP-2) biodegradable site to allow NO delivering in a well-controlled manner. Nanomatrix increased the viability of murine $\beta$-cells (MIN-6 cells), as well as the production of insulin under glucose stimulation, which was dependent on the NO release from gels, particularly at low rates $(32.5 \mathrm{mmol}$ and $35 \mathrm{mmol}) .{ }^{109}$ However, optimizing this approach in order to discard any risk of negative effects derived from $\mathrm{NO}$ before considering using Nanomatrix-NO for clinical trials would be needed.

In an attempt to mimic the angiogenic activity of heparin, the heparin-mimetic peptide hydrogel HM-PA was designed to favor angiogenesis and to bind growth factors involved in wound repairing. HM-PA is another $\beta$ sheet structured hydrogel that offers a heparin-like bioactivity and succeed to promote the viability and function of murine islets when cultured along with FGF and VEGF for 7 days. Moreover, the transfer of murine islets encapsulated within HM-PA hydrogels restored euglycemia during 28 days in diabetic rats, as a higher production of insulin, and angiogenesis was recorded in comparison to the transfer of islets without gels. ${ }^{17}$

Further research explored the biofunctionalization of amphiphilic peptides with the biomimetic GLP-1 receptor Ser [2] exendin (HSEDTFTSD) to form $\alpha$-helix based nanofibrillar self-supported hydrogels capable of allowing the culture of murine insulin-producing cells (RIN-m5F cells). GLP-1 hydrogels successfully supported the viability of murine $\beta$-cells in $3 \mathrm{D}$ cultures and promoted the production of insulin in a greater extent in comparison to exendin-4 under inflammatory conditions. ${ }^{110}$ These studies highlight the remarkable advantages that SAPHs offer to restore euglycemia. However, the development of refined protocols to allow a precise control of functionalities to direct cellular functions is still undergoing.

Furthermore, the incorporation of whole proteins to improve the functions of pancreatic cells has also shown good results. For instance, the KLD12 peptide hydrogel, when mixed with the negatively charged heparin known to have affinity to the hepatocyte growth factor (HGF), VEGF, and the fibroblastic growth factor (FGF), favored the retention of heparin and HGF through electrostatic interactions, which led to help the viability of murine $\beta$-cells and the production of insulin in 3D cell cultures under inflammatory conditions. In addition, the infiltration of $\mathrm{T}$ lymphocytes and the expression of IL-1 were significantly reduced after KLD2R treatment in vivo, which according to the authors could be majorly facilitated by HGF. ${ }^{95}$ Previously, the KLD2R hydrogel functionalized with biological cues belonging to fibronectin, and collagen improved the production of insulin from murine $\beta$-cells in vitro. ${ }^{96}$

Other examples for the cellular treatment of DM involved the use of self-assembling heparin-binding peptide amphiphiles nanofibers for the delivery of VEGF and 
the fibroblast growth factor-2 (FGF-2), which successfully induced vascularisation and improved engraftment of syngeneic islets, when transplanted in a diabetic mouse with maintaining normoglycemia in a high proportion of the tested animals. ${ }^{98}$ Moreover, PuraMatrix ${ }^{\mathrm{TM}}$ was used as vehicle for the sustained release of murine insulin after subcutaneous injection in rats. Sustained release of murine insulin was achieved from this simple formulation, which maintained low blood glucose level for 24 hours in rats. ${ }^{97}$

Today, most peptide formulations designed in the field offer good biocompatibility, however, the potential immunogenicity derived from peptides itself or peptide-derived aggregates is still controversial. ${ }^{11-113}$ This fact makes it necessary to carry out further research to discard any immunological effects related to peptide gels, when transferred into pancreatic tissues in vivo, before considering their therapeutic applications.

Overall, although the aforementioned studies discussed here highlight the significant role that peptide hydrogels have to protect $\beta$-cells from harsh environments and allow their biological functions in a well-controlled manner (Figure 2B), some relevant facts still need to be considered to place peptide gels as a cutting-edge technology for treating hyperglycemia. One major factor to be considered is the rational use of primary human cells under harsh enzymatic microenvironments that better reflect the human physiological conditions. This turns out relevant, since, despite the remarkable biochemical features attributed to SAPHs, their mechanics and stability are two major concerns, which is mainly true when they are subject to in vivo environments, since SAPHs are inherently dynamic, biodegradable, and fluctuant scaffoldings susceptible to temperature and enzymatic activity. This ultimately leads to their easy erosion and degradation. ${ }^{83,100,101,114}$ Another key factor is time, thus, using long kinetics during research is needed to push the mechanics and stability of peptide gels to their boundaries, which ultimately would facilitate the acquisition of reliable outcomes to determine the suitability of SAPHs as effective $3 \mathrm{D}$ vehicles to restore euglycemia and to improve islets grafting with no doubts of premature degradation. ${ }^{104,105}$

\section{Self-Assembled Peptide}

Formulations for Obesity Treatment

Some studies have focused on the design and development of novel self-assembled peptide formulations (nonhydrogels) to address obesity. The lipopeptide PYY is a gastrointestinal hormone involved in the reduction of appetite following food intake. In an attempt to obtain PYY analogous offering effective, more stabilized and safe anti-obesity properties, it has been explored the design of three PYY derivates, which acquire $\beta$-hairpin and $\alpha$-helix nanostructured conformations in solution. Following lipidation via palmitoyl chains linked to three different positions, particularly in residues serine (position 11), and arginine (positions 17 and 23) throughout the peptide backbone, various nanostructured matrices such as $\alpha$-helix based micelles, $\beta$-hairpin nanofibrils, and nanotapes could be formed. Such peptide conformations assembled under physiological $\mathrm{pH}$ and in a temperature-dependent manner. Hence, the synthetic PYY formulations could facilitate the development of novel peptide solutions or peptide hydrogels with high potential to be used as pharmaceutics to address obesity in a more stable and extended manner in comparison to medications, such as Liraglutide. ${ }^{26}$ Nevertheless, further research would shed light for a deeper understanding of the assembly of PYY peptides to develop effective and safer anti-obesity drugs.

In 2014, Pellegrinelly et al reported that human adipocytes isolated from obese patients decreased their lipolysis activity after following mechanical compression when encapsulated in RADA16-II. Furthermore, adipocytes increased their expression rates of proinflammatory cytokines, fibrotic molecules and collagens. Interestingly, such cellular responses observed within gels after mechanical stress, are strongly linked to impaired lipid mobilization and the formation of fibrotic adipocyte tissue in obese subjects, which ultimately leads to insulin resistance. Therefore, this study highlights the key role that $\beta$-sheet SAPHs have as 3D extracellular mimicking platforms to facilitate basic research to understand and elucidate relevant biological responses for biomedical applications. ${ }^{115}$

\section{Self-Assembled Peptides for Treatment Cardiovascular Affections}

As mentioned above, acute myocardial infarction (AMI) represents a serious public health problem around the world. Unfortunately, the current therapeutics to address AMI, which include pharmacotherapy, ventricular assist devices, dialysis, as well as surgical procedures are not capable of restoring cardiac functions yet. ${ }^{116,117}$ In this regard, acellular and cell-load SAPHs arise as an promising route to carry and deliver biomimetic molecules and 


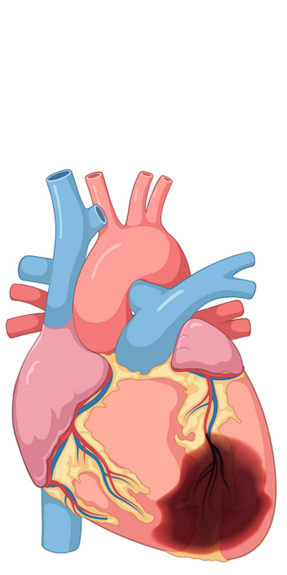

Hischemic tissue
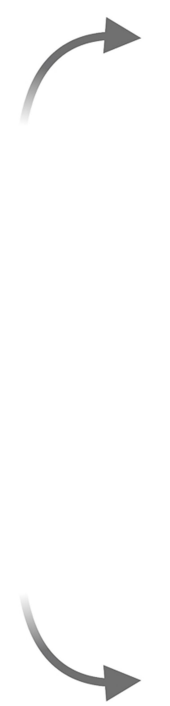

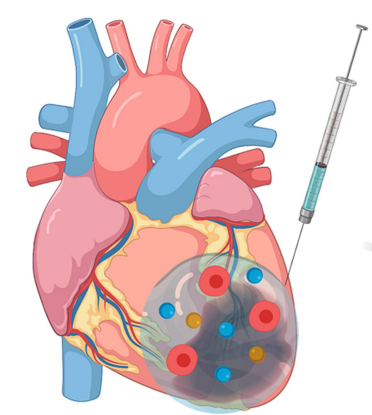

Peptide hydrogel coating

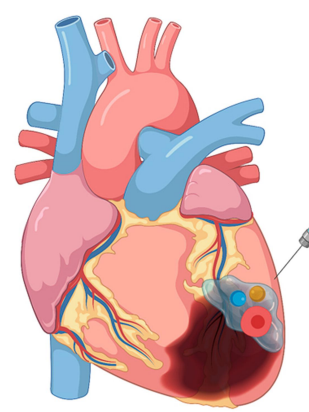

Intracardiac peptide hydrogel

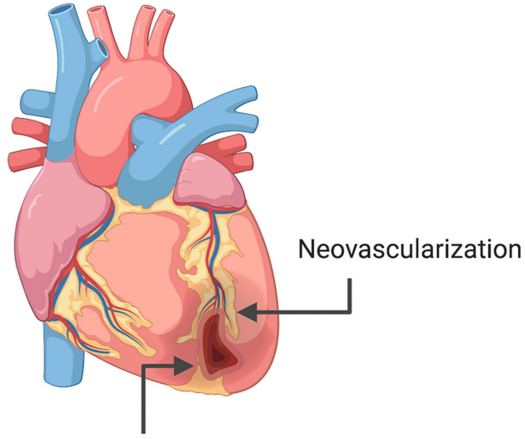

Damage reduction

Figure 3 Schematic representation of self-assembling peptide hydrogels for cardiovascular tissue regeneration. Growth factors, drugs or stem cells are incorporated in peptide hydrogels to promote cardiac tissue healing.

drugs in an attempt to overcome such medical complications (Figure 3). ${ }^{118}$

\section{Acellular Self-Assembled Peptide Hydrogels as Biologics for Heart Attack Treatment}

The formation of fibrotic tissue during AMI is one major concern in medicine. Therefore, efforts are being carried out to prevent and to reduce fibrosis during tissue repair in patients undergoing AMI. ${ }^{22}$ In this context, composite hydrogels have been designed from natural-derived materials, such as chitosan, collagen, and hyaluronic acid, which have succeeded to encapsulate and deliver various growth factors, such as angiopoietin-1, insulin-like growth factor-1 (IGF1), VEGF, and stromal cell-derived factor $1 \alpha$ (SDF1a). ${ }^{92,119-121}$ However, over naturally derived scaffolds, SAPHs arise as advantageous scaffoldings in terms of reproducibility and stability, since they avoid batch-to-batch variability, which is significant for biomedical applications. ${ }^{122-124}$

Recently, Han et al designed the PGN peptide hydrogel from two short peptide sequences GHRPS, a secretagogue known to offer cardioprotective activity, and GTAGLIGQ a peptide that belongs to matrix metalloprotease-2 (MMP-2). The latter has been incorporated into the system to assist in the disassociation of PGN. Additionally, naphthalene acetyl tail linked to the N-terminus of a phenylalanine dipeptide or NapFF was incorporated to promote gelation. The PGN hydrogel supported the viability of murine myoblasts under oxidative stress conditions, which might be due to GHRPS. Furthermore, exosomes derived from human mesenchymal cells (derived from the umbilical cord) encapsulated in the PGN gel, favored the expression of transforming growth factor-beta (TGF- $\beta$ ), whilst the infiltration of inflammatory cells decreased once such formulation was transferred into an infracted model in vivo. Moreover, the formation of fibrotic tissue was significantly reduced, whereas angiogenesis improved for 28 days after intracardiac gel treatment. ${ }^{125}$

Similarly, RADA16-II was functionalized with the peptide sequence CDDYYYGFGCNKFCRPR to mimic the bioactivity of Notch 1 ligand (regulator of cell proliferation, maturation, and apoptosis). RADA16-CDDYYYGFGCN KFCRPR decreased fibrosis, stimulated angiogenesis, and favored the recruitment of stem cells in an infracted model in vivo. ${ }^{22}$ 
Therefore, the studies presented emphasize the key role that biofunctionalized SAPHs have to improve cardiac functions and cardiac tissue regeneration in a simplistic and cost-effective manner with no need of incorporating whole proteins or complicated chemistry strategies.

Previously, Kim et al encapsulated both the plateletderived growth factor (PDGF) and FGF2 in RADA16-II for their progressive and sustained delivery once transferred into an infarcted heart model. The administration of RADA16-II gel significantly reduced apoptosis, as well as cardiac wall thickness, which improved cardiac functions during 4 weeks of treatment ${ }^{91}$ as represented in Figure 3.

Moreover, two hydrophobic cardiovascular drugs, Quinine and Pindolol (non-selective adrenergic receptor blockers) were successfully incorporated within RADA16-II peptide hydrogel to promote their retention and sustained releasing. The incorporation of such drugs in RADA16-II did not affect its $\beta$-sheet conformation nor its self-assembly. After the encapsulation of the hydrophobic drugs in gels, their cumulative and sustained release could be successfully achieved in one week. According to the authors, such drug retention and release were significantly promoted by electrostatic interactions occurring between the aromatic rings of medications and the nanofibers forming RADA16-II. This outcome was also dependent on the isoelectric point of medications (close to $\mathrm{pH} 7$ ), $\log \mathrm{P}$, and the type of saline buffers used to dilute the drugs. Hence, further investigations must to be carried out for a deeper understanding of the physicochemical mechanisms (for example, drug diffusion) under physiological $\mathrm{pH}$ to allow the delivery of cardiovascular drugs from RADA16-II gels. $^{90}$

\section{Self-Assembled Peptide Hydrogels as Cell-Load Biologics for Heart Attack Treatment}

Over the years, the transfer of stem and mature cells became as a general approach to the treatment of CVDs, such as AMI, in an attempt to restore cardiac functions in vivo. Nonetheless, poor cell retention and impaired stem cell differentiation are concerns that still limit such a strategy. ${ }^{126-129}$

In this context, RADA16-II as a three-dimensional depot of cells supported the viability of murine MSCs once transferred into beating hearts of rats subjected to coronary artery ligation. Thereafter, gel treatment improved cardiac functions and decreased ventricular dilatation in 28 days. In addition, a high rate of genes related to tissue repair, and an anti-inflammatory response could be recorded in the myocardium, as well as the formation of microvasculature and a reduced deposition of interstitial collagen could be observed after hydrogel treatment in vivo. It is believed that such outcomes could be derived from the paracrine activity of MSCs once delivered from RADA16-II. According to the authors, RADA16-II can be easily prepared and applied by practitioners, which is a major advantage for biomaterials intended for clinical applications. $^{24}$

In order to direct stem cell differentiation, the nanofibrillar-based peptide hydrogel ${ }^{\mathrm{D}}$ FEFKDFEFKYRG ${ }^{\mathrm{D}}$, was used to encapsulate murine MSCs genetically modified to increase the production of the hepatocyte growth factor (HGF), which has shown to play a key role as an antifibrotic, proangiogenic and cardioprotective molecule. The transfer of the peptide hydrogel harboring the engineered MSCs into infarcted animals promoted a significant improvement in heart functions as scarring in myocardial tissue decreased as represented in Figure 3. Furthermore, it was suggested that ${ }^{\mathrm{D}}$ FEFKDFEFKYRG ${ }^{\mathrm{D}}$ was key to facilitate cellular adhesion, viability and the commitment of MSCs into a cardiomyocyte profile. ${ }^{130}$

The double functionalization of RADA-16-II with RGD and KLT (the latter known to provide angiogenic activity) also showed a remarkable retention of murine bone marrow mesenchymal stem cells once transferred into murine cardiac tissue. Furthermore, reduced infarcted areas and the proliferation of cardiomyocytes were evidenced after 28 days of hydrogel treatment, ${ }^{131}$ which is in good agreement with the research carried out by $\mathrm{Li}$ and Guo, who showed that RADA16-RGD significantly promoted the retention of marrow derived cardiac stem cells (MCSCs), when cultured on gels under anoxic and low glucose conditions in vitro. Moreover, RADA16-RGD hydrogels significantly repaired myocardium and improved cardiac functions as myocyte contractions increased and the reduction of collagen deposition was observed in a murine AMI model. ${ }^{132}$

The capability of RADA16-II to maintain the plasticity of human induced pluripotent stem cells (hiPSCs) under $3 \mathrm{D}$ conditions has been explored to develop bioactive patches capable of promoting myocardial reparation. Molecular biology tests showed that hiPSCs in RADA16-II showed good viability and maintained their plasticity, since POU5F1 and FOXA2 were upregulated 
and downregulated, respectively under ascorbic acid (a cell differentiation inducer) stimulation for 20 days of $3 \mathrm{D}$ culture. Additionally, the expression of the gene $T B X 5$ (another cardiac progenitor), was unchanged under the same cell culture conditions. On the other hand, hiPSCs expressed the cardiac lineage genes GATA4 and $T B X 5$, and downregulated the expression of POU5F1 (a pluripotential marker) under ascorbic acid stimulation by using standard cell cultures. These data strongly suggest that RADA16-II is a useful scaffold to encapsulate and deliver pluripotent cells in a well-controlled manner without inducing premature cell differentiation, which represents a significant advantage to direct cellular differentiation to ultimately help with the formation or repair of cardiovascular tissues. However, further studies for a better understanding of the plasticity of hiPSCs in RADA16-II hydrogels for the treatment of cardiovascular tissue would be needed. ${ }^{133}$

Similarly, in 2014 Soler et al developed a cardiac implant from RADA16-II, in which they encapsulated progenitor cells derived from subcutaneous adipose tissue (SubATDPCs) of patients undergoing cardiac surgery. This approach focuses on directing cardiac cell differentiation after hydrogel implantation into an AMI model to promote the regeneration of affected cardiac tissue as exemplified in Figure 3. Interestingly, the viability of SubATDPCs significantly improved, and blood vessel formation was observed, which $^{134}$ is in good agreement to previous studies showing the suitability of RADA16-II to support the $3 \mathrm{D}$ culture of cardiac cells to prevent irregular contractions of cardiomyocytes. ${ }^{135}$ However, regarding previous research, it is necessary to explore in a deeper way the cardiac tissue functions, where immunological reactions can be discarded as for premature disassociation of gels to facilitate the clinical transfer of RADA16-II to restore cardiac malfunctions.

\section{Self-Assembled Peptides as Cell- Load Biologics for Treating Other CVD Disorders}

One major goal for biomedicine is finding novel alternatives to replace damaged vascular tissue. Today, one general approach to overcome such medical complication includes vascular grafting. However, following grafting surgery, restenosis, partial endothelialization and thrombosis are some vascular complications related to grafting that still need improvements. In this matter, recent studies explore the capability of peptide hydrogels to form vascular-like nanostructures matrices to restore the architecture and function of vessels. ${ }^{93}$ For instance, the double functionalization of RADA16-II with QLK and LRK peptides has explored to induce the formation of vascular tissue. The peptide QLK is known to bind transglutaminase (via covalent interactions), whose function is to provide protection to growth factors from proteolytic degradation, while LRK has the capability to join angiogenic inducers, such as HGF, and VEGF. Therefore, through blending RADA16QLK and RADA-LRK peptides, a double functionalized RADA-QLK-LKR was formed and transferred onto chicken chorioallantoic membranes to induce the formation of blood vessels-like tissue in situ. The retention of the functionalized RADA-II peptide gel was significantly facilitated by strong electrostatic interactions between LRK and heparan sulfate. Through a minimalist approach, the peptide hydrogel supplemented with VEGF and HGF also supported the culture of human umbilical vein endothelial cells (HUVECs) when cultured on gels, as well as the formation of capillary-like tubular structures at 8 hours of culture in vitro. ${ }^{93}$

Similarly, McClendon et al used the amphiphilic peptide $\mathrm{C}_{16}-\mathrm{V}_{3} \mathrm{~A}_{3} \mathrm{E}_{3}\left(\mathrm{NH}_{2}\right)$ to form a hydrogel mimicking the tubular shape of coronary arteries. To achieve this, the amphiphile peptide solution was injected into a shear flow chamber, which, subsequently, was placed into saline solution to induce gelation. After this, human smooth muscle cells were encapsulated in the peptide gel and were subjected to contractional and rotational motion in order to emulate blood flow and endothelial contraction. The viability of cells was steady, and interestingly, cells acquired an elongated morphology after 12 days of culture. In addition, cells were capable of migrating to the surface of hydrogels and aligned throughout the tubular shaped gel, where higher rates of cellular growth were recorded in comparison to cells not subjected to contractional and rotational stimuli. The outcome reported from this study, makes amphiphile peptide hydrogels appealing scaffolds to form tubular structures capable of repairing damaged arteries in patients with heart disease. ${ }^{136}$

Through a different approach to target vascular disorders, the role that NO has to foster the proliferation of smooth cells has been evaluated, since NO is known to be a natural mediator of vascular homeostasis and an inducer of endothelial cells proliferation. Therefore, the amphiphile peptide hydrogel GTAGLIGQ was functionalized with both, YIGSR and KKKKK, which are laminin- 
derived adhesion and nitrogen oxide (NO) donating moieties, respectively. The peptide gel also incorporated a MMP2 mediated cleavage site to favors its progressive enzymatic degradation and the subsequent release of YIGSR and KKKKK. Thereafter, the hydrogel was used as a coating for silicone-based cell cultures chambers, which were supplied with NO. The incorporation of NO into the cell culture chambers and its subsequent release from cell culture significantly enhanced the adhesion and proliferation of endothelial cells, contrary to the observed with smooth muscle cells, whose proliferation was limited after $48 \mathrm{~h}$ on $2 \mathrm{D}$ cultures. ${ }^{137}$ Consequently, this approach might be useful to improve the conditions of cardiovascular implants and reduce risks associated to cardiovascular therapeutics in the near future.

Atherosclerosis is another cardiovascular condition that requires more effective therapies. Therefore, the propensity of the short bioactive peptide hemopressin (PVNFKFLSH) to form $\beta$-sheet-based nanofibrillar matrices to prevent atherosclerosis was investigated. Hemopressin is known to inhibit food intake in vivo through an antagonist effect on the cannabinoid receptor CB1. According to some authors, synthetic hemopressin (PVNFKFLSH) is able to self-assembly under physiological $\mathrm{pH}$ environments, however, the formation of ordered and unordered nanostructures from such peptide has also been reported. Although, this strategy represents a plausible route for discovering novel pharmaceutics to address atherosclerosis, further research would be needed to fully understand the hierarchical assembly of PVNFKFLSH to discard the risk of any peptide fibrillization that may carry non-desirable biological effects. ${ }^{138}$

In this context, another research studied the capability of the self-assembling cyclic peptide c(wLwReQeR) to control the morphology and function of the high-density lipoprotein (HDL). Importantly, the architecture of the HDL molecules is strongly linked to their capability to regulate cholesterol levels in blood. The cyclic peptide $\mathrm{c}$ (wLwReQeR) was designed to form structured nanotubes capable of arresting lipids from HDL particles, and subsequently, of increasing the formation of lipid-poor HDL or pre-beta-HDL in vitro and in vivo. The mechanisms involved in this approach are not yet fully understood, however, according to the authors the cyclic peptides are capable of displacing the apoA-I protein forming $\mathrm{HDL}$ particles, which ultimately favors the releasing of the lipid-free apoA-I. Therefore, the latter molecule is capable of accepting lipids and cholesterol facilitating the subsequent transport and degradation of apoA-1. This useful approach might avoid the accumulation of apoA-1 in vessels, and thus, controlling the progression of atherosclerotic plaques. ${ }^{139}$

\section{Pathway Towards Development of Medicinal Products Based on Self- Assembling Peptides for Clinical Treatment of MS Conditions}

In the last two decades, there has been a surge of endeavours to develop therapeutic systems based on self-assembling peptides for various medical conditions, with most research carried out focusing on regenerative medicine and drug delivery approaches. The majority of these studies were confined to proof-of-concept with insufficient preclinical research, which refrain the progression towards clinical trials. Leading medical regulatory authorities worldwide, such as the US Food and Drug Admnistration (FDA), Medicines and Healthcare products Regulatory Agency (MHRA) in the UK, European Medicines Agency (EMA), and Ministry of Health, Labour and Welfare (MHW) of Japan, have set rigorous regulations for clinical trial authorization of any medicinal product or device; with the patient's safety, and product quality, and efficacy at the centre of the development process. Common quality, safety, and efficacy guidelines have been agreed between the aforementioned leading authorities and pharmaceutical industry through the International Council for Harmonisation (ICH) of technical and scientific requirements for products for human use. ${ }^{140}$ These guidelines should be followed throughout all development stages of self-assembling peptide products for clinical use including those intended for treatment of MS conditions. In this section, we will shed the light on few examples of studies that reported preliminary pre-clinical results that have good chances of clinical translation with more extensive studies needed to meet the pre-clinical requirements of regulators for clinical trials authorization.

As discussed earlier in our recent review, good steps have been taken towards developing advanced biomaterials for the cellular and acellular treatment of diabetes mellitus (DM) and associated complications, which led to few FDA approved products. ${ }^{86}$ However, systems based on self-assembling peptides have not gone that far. A preclinical study showed promising results for the cellular treatment of DM using self-assembling heparin-binding peptide amphiphiles nanofibers for the delivery of vascular 
endothelial growth factor (VEGF) and FGF-2, which successfully induced vascularisation and improved engraftment of isologous islets of Langerhans when transplanted in diabetic mouse with maintaining normoglycemia in high proportion of the tested animals (Table 4).$^{98}$ PuraMatrix ${ }^{\mathrm{TM}}$ peptide hydrogels on the other hand were used for the acellular drug treatment of DM, where hydrogels were used as vehicles for the sustained release of murine insulin post-subcutaneous injection in rats. Sustained release of murine insulin was achieved from this simple formulation, which maintained low blood glucose level for 24 hours in rats. ${ }^{97}$ A smart glucose responsive hydrogel system has also been reported and showed a good potential for the on-demand insulin release for clinical translation. The system is based on the selfassembling $\beta$-hairpin forming IA-2 peptide hydrogel loaded with glucose oxidase (GO) and bovine insulin (Table 4) ${ }^{141}$ In hyperglycaemia conditions, GO acts as a catalyst that converts glucose to gluconic acid, lowering the hydrogel $\mathrm{pH}$ and cationic residues become charged leading to repulsion and unfolding of peptide chains and consequently disassembly and insulin release. The system proved to work very well in vivo providing physiological control of insulin release, where diabetic mice treated with this formulation showed higher blood insulin concentrations and reduction in glucose levels compared to groups treated with insulin loaded hydrogels without GO. ${ }^{141}$

Chronic wounds and ulcers are of the main complications associated with DM, which can eventually lead to limb surgical amputation in severe conditions. ${ }^{142}$ Heparinlike amphiphilic peptide hydrogels improved wound healing in diabetic mice, as it forms a biomimetic scaffold functionalized with the negatively charged heparin sulphate proteoglycans, hence, capable of binding the angiogenic factor VEGF and the fibroblast growth factor FGF-2 (Table 4). ${ }^{143}$ This system provides both structural and functional attributes that enhanced vascularization, expression of $\alpha$-smooth muscle actin ( $\alpha$-SMA), collagen deposition and re-epithelisation, as well as the induced reduction in the levels of inflammatory cytokines (IL-6 and TNF- $\alpha$ ) levels. Good chances can be seen here for formulation prototype development of a pharmaceutical product for the treatment of diabetic chronic wounds and ulcers. ${ }^{143}$ Another complication associated with DM is the erectile dysfunction in male patients, which was shown to be closely related to the high collagen levels in cavernous tissue. Interestingly, a recent study showed that significant reduction of the cavernosa collagen levels of rat models was observed over on 4 days after localized injection with Sonic Hedgehog loaded amphiphilic peptide hydrogels (Table 4). This approach introduces a new therapeutic strategy for erectile dysfunction in male diabetic patients. ${ }^{144}$

For the treatment of myocardial infarction, the development of cardiac patches based on self-assembling peptide for the cellular therapy of myocardial infarction has been patented. The patch is a prototype of a medical device composed of stitchable biodegradable polyurethane-based film support covered with a polycaprolactone (PCL) based biopolymer composite, which is impregnated with an ionic-complementary $\beta$-sheet forming peptide hydrogel as a nanofibrous functionalized scaffold that mimics extracellular matrix microenvironment. Patches implanted on the left ventricle of rats after heart cryoinjury showed to be stable for 4-10 days after implantation and provided structural support to damaged tissue without signs of inflammation. The patent suggested that this device is adequate for autologous stem cells implantation not only for cardiac tissue engineering, but also for any soft tissues. ${ }^{145}$

Another example of pre-clinical studies for myocardial infarction treatment involved the use of the insulin-like growth factor 1 (IGF-1) functionalized peptide nanofibers. In this system, the biotinylated cardiomyocyte IGF-1 was conjugated with streptavidin, which in turn was complexed with the biotinylated self-assembling ionic-complementary RADA16-II peptide forming IGF-1 functionalized $\beta$-sheet nanofibers. Preliminary in vivo studies showed that the biotin "sandwich" conjugate has supported cardiac tissue repair, where it provided sustained delivery of IGF-1 for 28 days, post-injection into rat myocardium. When combined with cardiomyocytes transplantation, the growth factor-peptide nanofibers conjugate not only acted as a sustained delivery vehicle for IGF-1, but also as a 3D scaffold system for transplanted cells, thus significantly improving cardiac tissue structure as evident by increased cross-sectional area and function by improving systolic activity (Table 4). Local myocardial insulin-like growth factor 1 (IGF-1) delivery with biotinylated peptide nanofibers improves cell therapy for myocardial infarction. ${ }^{120}$

Another study demonstrated the multifunctional role of RADA16-II peptide nanofibers as biomimetic 3D cell scaffolds for recruiting endothelial and vascular smooth muscle cells and as a delivery vehicle for the angiogenic fibroblast growth factor-2 (FGF-2) and the arteriogenic platelet-derived growth factor-BB (PDGF-BB); a new 
Table 4 Depiction of Bottom-Up Design Approach for De Novo Peptides Capable of Self/Co-Assembly into Different Classes of Bioinspired Nanofibrous Structures Forming Hydrogels.

\begin{tabular}{|c|c|c|c|c|c|}
\hline $\begin{array}{l}\text { Therapeutic } \\
\text { Molecule }\end{array}$ & Self-Assembling Peptide System & $\begin{array}{l}\text { MS } \\
\text { Condition }\end{array}$ & Treatment Mechanism & $\begin{array}{l}\text { Development } \\
\text { Stage }\end{array}$ & Ref. \\
\hline $\begin{array}{l}\text { Streptavidin- } \\
\text { Biotin-IGF-I. }\end{array}$ & $\begin{array}{l}\beta \text {-sheet ionic-complementary peptide. } \\
\text { Ac-RARADADARARADADA-Biotin } \\
\text { (RADA I6-II-Biotin). }\end{array}$ & $\begin{array}{l}\text { Myocardial } \\
\text { infarction. }\end{array}$ & $\begin{array}{l}\text { Sustained myocardial growth factor } \\
\text { delivery improved cardiac cross-sectional } \\
\text { area and systolic function. }\end{array}$ & Pre-clinical & 120 \\
\hline $\begin{array}{l}\text { FGF-2 and } \\
\text { PDGF-BB. }\end{array}$ & $\begin{array}{l}\beta \text {-sheet ionic-complementary peptide. } \\
\text { Ac-RARADADARARADADA- } \\
\text { CONH }_{2} \text { (RADAI6-II). }\end{array}$ & $\begin{array}{l}\text { Myocardial. } \\
\text { infarction. }\end{array}$ & $\begin{array}{l}\text { Combination therapy. Protect cardiac tissue } \\
\text { by inhibiting fibrosis and enhancing } \\
\text { vascularity. Peptide nanofibers act as 3D } \\
\text { scaffolds for recruiting endothelial and } \\
\text { vascular smooth muscle cells, and as a } \\
\text { delivery system for angiogenic growth factor } \\
\text { FGF-2 and arteriogenic growth factor } \\
\text { PDGF-BB. }\end{array}$ & Pre-clinical & 91 \\
\hline N/A & $\begin{array}{l}\text { Cardiac patch including a PCL-based } \\
\text { biopolymer composite layer } \\
\text { impregnated with } \beta \text {-sheet ionic- } \\
\text { complementary peptide hydrogel. } \\
\text { FEFEFKFK, VEVEVKVK, } \\
\text { PGSPFEFEFKFK, IGF-FEFEFKFK. }\end{array}$ & $\begin{array}{l}\text { Myocardial } \\
\text { infarction. }\end{array}$ & $\begin{array}{l}\text { Layer of peptide-functionalized biopolymer } \\
\text { composite that acts as biomimetic } \\
\text { structural scaffold for cellular therapy of } \\
\text { myocardial infarction. }\end{array}$ & Pre-clinical & 145 \\
\hline $\begin{array}{l}\text { VEGF and } \\
\text { FGF-2 growth } \\
\text { factors. }\end{array}$ & Heparin-binding peptide amphiphiles. & $\begin{array}{l}\text { Diabetes } \\
\text { mellitus }\end{array}$ & $\begin{array}{l}\text { Delivery of growth factors that enhanced } \\
\text { vascularization and islets of Langerhans } \\
\text { engraftment. }\end{array}$ & Pre-clinical & 98 \\
\hline $\begin{array}{l}\text { Heparin, } \\
\text { VEGF, and } \\
\text { FGF-2. }\end{array}$ & $\begin{array}{l}\beta \text {-sheet ionic-complementary peptide. } \\
\text { Ac-(RADA })_{4}-\mathrm{CONH}_{2} \\
\left(\text { PuraMatrix }{ }^{\mathrm{TM}}\right) \text {. }\end{array}$ & $\begin{array}{l}\text { Diabetes } \\
\text { mellitus. }\end{array}$ & $\begin{array}{l}\text { Sustained delivery of murine insulin post } \\
\text { subcutaneous injection. }\end{array}$ & Pre-clinical & 97 \\
\hline Bovine insulin. & $\begin{array}{l}\beta \text {-hairpin peptide. } \\
\text { IKIKIKIK-I'PPPT-KIOIKIKI-NH } 2 \\
\text { (IA2) with glucose oxidase. }\end{array}$ & $\begin{array}{l}\text { Diabetes } \\
\text { mellitus. }\end{array}$ & $\begin{array}{l}\text { Glucose responsive hydrogel system for } \\
\text { the controlled on-demand release of } \\
\text { insulin. }\end{array}$ & Pre-clinical & 141 \\
\hline $\mathrm{N} / \mathrm{A}$ & Heparin-like amphiphilic peptide. & $\begin{array}{l}\text { Diabetic foot } \\
\text { ulcer. }\end{array}$ & $\begin{array}{l}\text { Enhanced vascularization, expression of } \alpha \text { - } \\
\text { smooth muscle actin ( } \alpha \text {-SMA), collagen } \\
\text { deposition and re-epithelization, as well as } \\
\text { induced reduction in the inflammatory } \\
\text { cytokines (IL- } 6 \text { and TNF- } \alpha \text { ) levels. }\end{array}$ & Pre-clinical & 143 \\
\hline $\begin{array}{l}\text { Sonic } \\
\text { Hedgehog. }\end{array}$ & $\begin{array}{l}\text { Lipidated peptide amphiphile. } \\
\mathrm{C}_{16}-\mathrm{V}_{2} \mathrm{~A}_{2} \mathrm{E}_{2}-\mathrm{NH}_{2} \text {. }\end{array}$ & $\begin{array}{l}\text { Erectile } \\
\text { dysfunction } \\
\text { (diabetes } \\
\text { mellitus } \\
\text { complication). }\end{array}$ & $\begin{array}{l}\text { Localized delivery of Sonic Hedgehog, } \\
\text { which decreases collagen production in } \\
\text { erectile fibres and enhance erectile } \\
\text { function. }\end{array}$ & Pre-clinical & 144 \\
\hline
\end{tabular}

Abbreviations: MS, metabolic syndrome; IGF-I, insulin-like growth factor-I; FGF-2, fibroblast growth factor-2; PDGF-BB, platelet-derived growth factor-BB; VEGF, vascular endothelial growth factor.

approach for myocardial infarction treatment. ${ }^{91}$ In this study, infarcted heart mice treated with the dual growth factor loaded RADA16-II hydrogels showed significant cardiac protection through enhanced vascularisation and inhibition of fibrosis compared to all control groups.
Peptide-based scaffoldings and their capability to be functionalized or combined with a plethora of biological components are exemplified in Table 4.

The above-chosen examples have very good chances for clinical translation; however, the main challenge for 
the clinical authorization here is the complicated nature of the prospective product, which is, in most cases, composed of three main components: self-assembling peptide nanostructures, growth factors or drug molecules, and cells (Figure 4).Therefore, more extensive pre-clinical testing following regulatory guidelines should be performed. This will involve, for instance, stability studies of the self-assembled peptide systems and the drug payload, level of impurities and evidence of good manufacturing practice in the development of the formulation or scaffold components. ${ }^{146}$ In addition, a full pre-clinical safety evaluation of the new systems should be performed, such as carcinogenicity, genotoxicity, reproductive toxicity and immunotoxicology studies. ${ }^{147}$ Moreover, a full evaluation of the specific quality and safety measures for biotechnological, cell therapy, and tissue engineering products is essential in case of the use of growth factors and/ or cells in the product. For instance, viral safety must be assured, cells viability in formulation and after administration, maintenance of genotype or phenotype for the intended treatment, etcetera ${ }^{146,148}$ as indicated in the ICH quality guidelines of technological product (Q5A-Q5E) ${ }^{146}$ and the EMA guidelines on human cell-based medicinal products. ${ }^{148}$ We believe that meeting the expectations of the regulators expectations equates with great potential of success for the bench-to-bed side development of selfassembling peptide products for clinical treatment of MS conditions. This success relies on the efficient interaction between research groups in universities, the pharmaceutical and biotechnology industry, and the regulators.

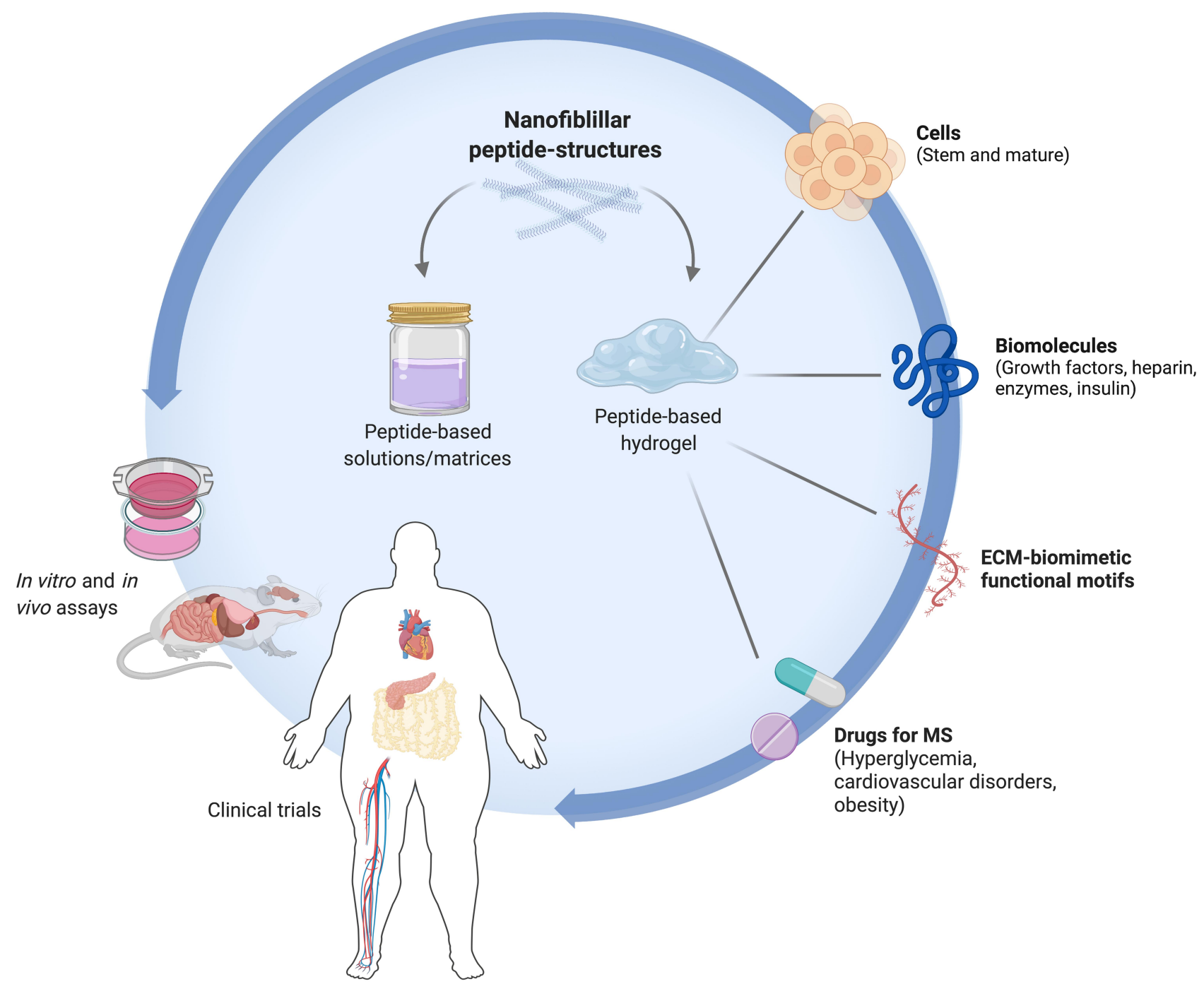

Figure 4 General outline of the peptide-based therapy (hydrogels, solutions, other matrices) for the treatment of metabolic syndrome and related comorbidities. Bioactive molecules, drugs or cells are usually incorporated in peptide-based nanostructures to provide them with specific therapeutic functionality. 


\section{Conclusion}

Metabolic syndrome is an unmet medical condition, which requires novel therapeutics to prevent and address its related comorbidities. In this context, self-assembled peptides represent a promising approach to overcome the limitations of current MS treatment. The recent studies discussed here shed light on the potential of self-assembling peptide nanostructures as a useful route for the discovery of novel drugs or to improvement of the current pharmaceuticals to face MS and derived diseases. Nevertheless, despite the physicochemical advantages that peptide-based technology offers in the biomedical field for regenerative medicine, tissue engineering and the pharmaceutical industry, only a limited peptide-based technology has reached clinical trials. This might be due to peptide-based nanomaterials as cutting-edge biotechnology still face some challenges to overcome, which include avoiding any potential immunogenicity reactions derived from novel peptide formulations designed, limited standardization protocols realted to the rate of biomolecules incorporated in peptide-base nanostructures to orchestrate biological functions, as well as short-term stability of peptide formulations when challenged under physiological conditions. Therefore, it is of paramount importance to carry out immunological studies in a deeper manner to identify any possible non-desirable immunogenicity derived from novel peptide-based formulations developed. Likewise, it may be advisable to extend evaluations of the biological responses after the rational incorporation of extracellular matrix peptide moieties, whole proteins, or drugs at different rates within peptide formulations. The aforementioned recommendations should be taken into account either at laboratory stages (ideally using human cells as biological platform to test the effect of peptide nanostructures developed) or during clinical stages following the recommendations of medical regulatory authorities. Moreover, we suggest the use of a double network approach when designing novel peptide-based nanomaterials, which could significantly improve their polymeric network density/strength and mechanical stability, while retaining their biological activity. Therefore, the transition from technological laboratory developments to the launch of peptide-based pharmaceutical products to meet MS, still requires further research efforts, where both research institutes and industry represent the fundamental basis to achieve such a goal.

\section{Disclosure}

The authors report no other potential conflicts of interest in this work.

\section{References}

1. Aguilar-Salinas CA, Viveros-Ruiz T. Recent advances in managing/understanding the metabolic syndrome. F1000Res. 2019; 8:370. doi:10.12688/f1000research.17122.1

2. Diabetes (World Health Organization) (2018).

3. Cardiovascular Diseases (CVDs. World Health Organization: 2017.

4. Obesity Update 2017. Organization for Economic Co-operation and Development; 2017.

5. Grundy SM. Drug therapy of the metabolic syndrome: minimizing the emerging crisis in polypharmacy. Nat Rev Drug Discov. 2006;5(4):295-309. doi:10.1038/nrd2005

6. Matfin G. Developing therapies for the metabolic syndrome: challenges, opportunities, and the unknown. Ther Adv Endocrinol Metab. 2010;1(2):89-94. doi:10.1177/2042018810375812

7. Ahadian S, Khademhosseini A. Smart scaffolds in tissue regeneration. Regen Biomater. 2018;5(3):125-128. doi:10.1093/rb/rby007

8. Bowerman CJ, Nilsson BL. Self-assembly of amphipathic $\beta$-sheet peptides: insights and applications. Biopolymers. 2012;98(3):169184. doi:10.1002/bip.22058

9. Ulijn RV, Smith AM. Designing peptide based nanomaterials. Chem Soc Rev. 2008;37(4):664-675. doi:10.1039/b609047h

10. Edwards-Gayle CJC, Hamley IW. Self-assembly of bioactive peptides, peptide conjugates, and peptide mimetic materials. Org Biomol Chem. 2017;15(28):5867-5876. doi:10.1039/c7ob01092c

11. Guilbaud JB, Rochas C, Miller AF, Saiani A. Effect of enzyme concentration of the morphology and properties of enzymatically triggered peptide hydrogels. Biomacromolecules. 2013;14 (5):1403-1411. doi:10.1021/bm4000663

12. Aggeli A, Bell M, Carrick LM, et al. $\mathrm{pH}$ as a trigger of peptide beta-sheet self-assembly and reversible switching between nematic and isotropic phases. $J$ Am Chem Soc. 2003;125 (32):9619-9628. doi:10.1021/ja021047i

13. Carrick L, Aggeli A, Boden N, Eileen Ingham JF, Waigh TA. Effect of ionic strength on the self-assembly, morphology and gelation of pH responsive $\beta$-sheet tape-forming peptides. Tetrahedron. 2007;63 (31):7457-7467. doi:10.1016/j.tet.2007.05.036

14. Acar H, Srivastava S, Chung EJ, et al. Self-assembling peptidebased building blocks in medical applications. Adv Drug Deliv Rev. 2017;110-111:65-79. doi:10.1016/j.addr.2016.08.006

15. Castillo Diaz LA, Saiani A, Gough JE, Miller AF. Human osteoblasts within soft peptide hydrogels promote mineralisation in vitro. J Tissue Eng. 2014;5:2041731414539344. doi:10.1177/ 2041731414539344

16. Kisiday J, Jin M, Kurz B, et al. Self-assembling peptide hydrogel fosters chondrocyte extracellular matrix production and cell division: implications for cartilage tissue repair. Proc Natl Acad Sci U S A. 2002;99(15):9996-10001. doi:10.1073/pnas.142309999

17. Uzunalli G, Tumtas $Y$, Delibasi $T$, et al. Improving pancreatic islet in vitro functionality and transplantation efficiency by using heparin mimetic peptide nanofiber gels. Acta Biomater. 2015;22:8-18. doi:10.1016/j.actbio.2015.04.032

18. Castillo Diaz LA, Elsawy M, Saiani A, Gough JE, Miller AF. Osteogenic differentiation of human mesenchymal stem cells promotes mineralization within a biodegradable peptide hydrogel. J Tissue Eng. 2016;7:2041731416649789. doi:10.1177/2041731416649789

19. Liu X, Wang X, Ren H, He J, Qiao L, Cui FZ. Functionalized selfassembling peptide nanofiber hydrogels mimic stem cell niche to control human adipose stem cell behavior in vitro. Acta Biomater. 2013;9(6):6798-6805. doi:10.1016/j.actbio.2013.01.027

20. Enateri V, Alakpa VJ, Lampel A, et al. Tunable supramolecular hydrogels for selection of lineage-guiding metabolites in stem cell cultures. Chem Cell Press. 2016;1:298-319. doi:10.1016/j. chempr.2016.07.001 
21. Zhang S. Discovery and design of self-assembling peptides. Interface Focus. 2017;7(6):20170028. doi:10.1098/rsfs.2017.0028

22. Boopathy AV, Martinez MD, Smith AW, Brown ME, García AJ, Davis ME. Intramyocardial delivery of notch ligand-containing hydrogels improves cardiac function and angiogenesis following infarction. Tissue Eng Part A. 2015;21(17-18):2315-2322. doi:10.1089/ten.TEA.2014.0622

23. Fosgerau K, Hoffmann T. Peptide therapeutics: current status and future directions. Drug Discov Today. 2015;20(1):122-128. doi:10.1016/j.drudis.2014.10.003

24. Ichihara Y, Kaneko M, Yamahara K, et al. Self-assembling peptide hydrogel enables instant epicardial coating of the heart with mesenchymal stromal cells for the treatment of heart failure. Biomaterials. 2018;154:12-23. doi:10.1016/j.biomaterials.2017. 10.050

25. Ouberai MM, Dos Santos ALG, Kinna S, et al. Controlling the bioactivity of a peptide hormone in vivo by reversible self-assembly. Nat Commun. 2017;8(1):1026. doi:10.1038/s41467-017-011 14-1

26. Hutchinson JA, Burholt S, Hamley IW, et al. The effect of lipidation on the self-assembly of the gut-derived peptide hormone PYY. Bioconjug Chem. 2018;29(7):2296-2308. doi:10.10 21/acs.bioconjchem.8b00286

27. Saklayen MG. The global epidemic of the metabolic syndrome Curr Hypertens Rep. 2018;20(2):12. doi:10.1007/s11906-0180812-z

28. Bonow RO. Primary prevention of cardiovascular disease: a call to action. Circulation. 2002;106(25):3140-3141. doi:10.1161/01 cir.0000048067.86569.e1

29. Huang PL. A comprehensive definition for metabolic syndrome. Dis Model Mech. 2009;2(5-6):231-237. doi:10.1242/dmm.001 180

30. NJ J, OGD J. Phatophysiology of the Metabolic Syndrome. In: Beck-Nielsen HE, editor. The Metabolic Syndrome. Vol. XI. Springer-Verlag Wien; 2013:229.

31. National Cholesterol Education Program (NCEP). Expert Panel on Detection Ea, and Treatment of High Blood Cholesterol in Adults (Adult Treatment Panel III). Third Report of the National Cholesterol Education Program (NCEP) Expert Panel on Detection, Evaluation, and Treatment of High Blood Cholesterol in Adults (Adult Treatment Panel III) final report. Circulation. 2002;106(25):3143-3421.

32. World Health Organization Regional Office for Europe (World Health Organization) (2020).

33. Diabetes Country Profiles. United States of America: World Health Organization; 2016.

34. Diabetes Country Profiles. Mexico: World Health Organization; 2016.

35. Magkos F, Yannakoulia M, Chan JL, Mantzoros CS. Management of the metabolic syndrome and type 2 diabetes through lifestyle modification. Annu Rev Nutr. 2009;29:223-256. doi:10.1146/ annurev-nutr-080508-141200

36. Grundy SM, Cleeman JI, Daniels SR, et al. Diagnosis and management of the metabolic syndrome: an American Heart Association/National Heart, Lung, and Blood Institute Scientific Statement. Circulation. 2005;112(17):2735-2752. doi:10.1161/ CIRCULATIONAHA.105.169404

37. Ma Y, Olendzki BC, Wang J, et al. Single-component versus multicomponent dietary goals for the metabolic syndrome: a randomized trial. Ann Intern Med. 2015;162(4):248-257. doi:10.7326/M14-0611

38. Buse JB, Ginsberg HN, Bakris GL, et al. Primary prevention of cardiovascular diseases in people with diabetes mellitus: a scientific statement from the American Heart Association and the American Diabetes Association. Diabetes Care. 2007;30 (1):162-172. doi:10.2337/dc07-9917
39. Berra K, Klieman L. National Cholesterol Education Program: adult Treatment Panel III-new recommendations for lifestyle and medical management of dyslipidemia. $J$ Cardiovasc Nurs. 2003;18(2):85-92. doi:10.1097/00005082-200304000-00003

40. Salas-Salvadó J, Fernández-Ballart J, Ros E, et al. Effect of a Mediterranean diet supplemented with nuts on metabolic syndrome status: one-year results of the PREDIMED randomized trial. Arch Intern Med. 2008;168(22):2449-2458. doi:10.1001/ archinte.168.22.2449

41. Deedwania P, Barter P, Carmena R, et al. Reduction of lowdensity lipoprotein cholesterol in patients with coronary heart disease and metabolic syndrome: analysis of the Treating to New Targets study. Lancet. 2006;368(9539):919-928. doi:10. 1016/S0140-6736(06)69292-1

42. National High Blood Pressure Education Program Working Group report on hypertension in diabetes. Hypertension. 1994;23(2):145-58;discussion 159-60. doi:10.1161/01.HYP. 23.2.145

43. Association AD. 9. Cardiovascular Disease and Risk Management. Diabetes Care. 2018;41(Supp11):S86-S104. doi:10. 2337/dc18-S009.

44. Whalen Karen FRPTA. Lippincott's Illustrated Reviews: Pharmacology. 6th ed. 2015.

45. Page MM, Watts GF. PCSK9 inhibitors - mechanisms of action. Aust Prescr. 2016;39(5):164-167. doi:10.18773/austprescr.2016. 060

46. Woolfson DN. Coiled-Coil Design: updated and Upgraded. Subcell Biochem. 2017;82:35-61. doi:10.1007/978-3-319-49674-0 2

47. Boyle AL, Bromley EH, Bartlett GJ, et al. Squaring the circle in peptide assembly: from fibers to discrete nanostructures by de novo design. $J$ Am Chem Soc. 2012;134(37):15457-15467. doi:10.1021/ja3053943

48. Gribbon C, Channon KJ, Zhang W, et al. MagicWand: a single, designed peptide that assembles to stable, ordered alpha-helical fibers. Biochemistry. 2008;47(39):10365-10371. doi:10.1021/ bi801072s

49. Rudra JS, Tripathi PK, Hildeman DA, Jung JP, Collier JH. Immune responses to coiled coil supramolecular biomaterials. Biomaterials. 2010;31(32):8475-8483. doi:10.1016/j.biomaterials.2010.07.068

50. Wang C, Stewart RJ, Kopecek J. Hybrid hydrogels assembled from synthetic polymers and coiled-coil protein domains. Nature. 1999;397(6718):417-420. doi:10.1038/17092

51. Zhang S, Lockshin C, Herbert A, Winter E, Rich A. Zuotin, a putative Z-DNA binding protein in Saccharomyces cerevisiae. EMBO J. 1992;11(10):3787-3796. doi:10.1002/j.1460-2075.1992.tb05464.x

52. Zhang S, Holmes T, Lockshin C, Rich A. Spontaneous assembly of a self-complementary oligopeptide to form a stable macroscopic membrane. Proc Natl Acad Sci U S A. 1993;90(8):33343338. doi:10.1073/pnas.90.8.3334

53. Zhang S, Lockshin C, Cook R, Rich A. Unusually stable betasheet formation in an ionic self-complementary oligopeptide. Biopolymers. 1994;34(5):663-672. doi:10.1002/bip.36034 0508

54. Wychowaniec JK, Patel R, Leach J, et al. Aromatic stacking facilitated self-assembly of ultrashort ionic complementary peptide sequence: $\beta$-sheet nanofibers with remarkable gelation and interfacial properties. Biomacromolecules. 2020;21(7):26702680. doi:10.1021/acs.biomac.0c00366

55. Aggeli A, Nyrkova IA, Bell M, et al. Hierarchical self-assembly of chiral rod-like molecules as a model for peptide beta -sheet tapes, ribbons, fibrils, and fibers. Proc Natl Acad Sci U S A. 2001;98(21):11857-11862. doi:10.1073/pnas.191250198

56. Swanekamp RJ, DiMaio JT, Bowerman CJ, Nilsson BL. Coassembly of enantiomeric amphipathic peptides into amyloidinspired rippled $\beta$-sheet fibrils. J Am Chem Soc. 2012;134 (12):5556-5559. doi:10.1021/ja301642c 
57. Lee NR, Bowerman CJ, Nilsson BL. Effects of varied sequence pattern on the self-assembly of amphipathic peptides. Biomacromolecules. 2013;14(9):3267-3277. doi:10.1021/bm400 $876 \mathrm{~s}$

58. Elsawy MA, Smith AM, Hodson N, Squires A, Miller AF, Saiani A. Modification of $\beta$-sheet forming peptide hydrophobic face: effect on self-assembly and gelation. Langmuir. 2016;32 (19):4917-4923. doi:10.1021/acs.langmuir.5b03841

59. Schneider JP, Pochan DJ, Ozbas B, Rajagopal K, Pakstis L, Kretsinger J. Responsive hydrogels from the intramolecular folding and self-assembly of a designed peptide. J Am Chem Soc. 2002;124(50):15030-15037. doi:10.1021/ja027993g

60. Ozbas B, Kretsinger J, Rajagopal K, Schneider JP, Pochan DJ. Salt-triggered peptide folding and consequent self-assembly into hydrogels with tunable modulus. Macromolecules. 2004;37:73 31-7337. doi:10.1021/ma0491762

61. Pochan DJ, Schneider JP, Kretsinger J, Ozbas B, Rajagopal K, Haines L. Thermally reversible hydrogels via intramolecular folding and consequent self-assembly of a de novo designed peptide. J Am Chem Soc. 2003;125(39):11802-11803. doi:10.1021/ja03 53154

62. Reches M, Gazit E. Controlled patterning of aligned selfassembled peptide nanotubes. Nat Nanotechnol. 2006;1(3):195200. doi:10.1038/nnano.2006.139

63. Sasselli IR, Pappas CG, Matthews E, et al. Using experimental and computational energy equilibration to understand hierarchical selfassembly of Fmoc-dipeptide amphiphiles. Soft Matter. 2016;12 (40):8307-8315. doi:10.1039/c6sm01737a

64. Smith A. Fmoc-Diphenylalanine self assembles to a hydrogel via a novel architecture based on $\pi-\pi$ interlocked $\beta$-sheets. Adv Mater. 2008;20(1):37-41. doi:10.1002/adma.200 701221

65. Gazit E. Self-assembly of short aromatic peptides: from amyloid disease to nanotechnology. NanoBiotechnology. 2005;1:286-288. doi:10.1007/s12030-005-0043-7

66. Abraham BL, Liyanage W, Nilsson BL. Strategy to identify improved n-terminal modifications for supramolecular phenylalanine-derived hydrogelators. Langmuir. 2019;35(46):1493914948. doi:10.1021/acs.langmuir.9b02971

67. Shi J, Gao Y, Yang Z, Xu B. Exceptionally small supramolecular hydrogelators based on aromatic-aromatic interactions. Beilstein J Org Chem. 2011;7:167-172. doi:10.3762/bjoc.7.23

68. Yang Z, Gu H, Zhang Y, Wang L, Xu B. Small molecule hydrogels based on a class of antiinflammatory agents. Chem Commun (Camb). 2004;(2):208-209. doi:10.1039/b310574a

69. Niece KL, Hartgerink JD, Donners JJ, Stupp SI. Self-assembly combining two bioactive peptide-amphiphile molecules into nanofibers by electrostatic attraction. J Am Chem Soc. 2003;125 (24):7146-7147. doi:10.1021/ja028215r

70. Cui H, Webber MJ, Stupp SI. Self-assembly of peptide amphiphiles: from molecules to nanostructures to biomaterials. Biopolymers. 2010;94(1):1-18. doi:10.1002/bip.21328

71. Mitra RN, Das D, Roy S, Das PK. Structure and properties of low molecular weight amphiphilic peptide hydrogelators. J Phys Chem B. 2007;111(51):14107-14113. doi:10.1021/jp076495x

72. Hartgerink JD, Beniash E, Stupp SI. Self-assembly and mineralization of peptide-amphiphile nanofibers. Science. 2001;294, (5547):1684-1688. doi:10.1126/science.1063187

73. Nowak AP, Breedveld V, Pine DJ, Deming TJ. Unusual salt stability in highly charged diblock co-polypeptide hydrogels. $J$ Am Chem Soc. 2003;125(50):15666-15670. doi:10.1021/ja038 1050

74. Deming Z. Tunable hydrogel morphology via self-assembly of amphiphilic pentablock copolypeptides. Soft Matter. 2010;6:25 46-2551. doi:10.1039/b927137f
75. Rughani R, Branco MC, Pochan DJ, Schneider JP. De novo design of a shear-thin recoverable peptide-based hydrogel capable of intrafibrillar photopolymerization. Macromolecules. 2010;43 (19):7924-7930. doi:10.1021/ma1014808

76. Maslovskis A, Guilbaud JB, Grillo I, Hodson N, Miller AF, Saiani A. Self-assembling peptide/thermoresponsive polymer composite hydrogels: effect of peptide-polymer interactions on hydrogel properties. Langmuir. 2014;30(34):10471-10480. doi:10.1021/la502358b

77. Li X, Gao Y, Kuang Y, Xu B. Enzymatic formation of a photoresponsive supramolecular hydrogel. Chem Commun (Camb). 2010;46(29):5364-5366. doi:10.1039/c0cc00163e

78. Qiu Z, Yu H, Li J, Wang Y, Zhang Y. Spiropyran-linked dipeptide forms supramolecular hydrogel with dual responses to light and to ligand-receptor interaction. Chem Commun (Camb). 2009; (23):3342-3344. doi:10.1039/b822840j

79. Huang Y, Qiu Z, Xu Y, Shi J, Lin H, Zhang Y. Supramolecular hydrogels based on short peptides linked with conformational switch. Org Biomol Chem. 2011;9(7):2149-2155. doi:10.1039/ c0ob01057j

80. Guilbaud JB, Vey E, Boothroyd S, et al. Enzymatic catalyzed synthesis and triggered gelation of ionic peptides. Langmuir. 2010;26(13):11297-11303. doi:10.1021/1a100623y

81. Rubio J, Alfonso I, Burguete MI, Luis SV. Interplay between hydrophilic and hydrophobic interactions in the self-assembly of a gemini amphiphilic pseudopeptide: from nano-spheres to hydrogels. Chem Commun (Camb). 2012;48(16):2210-2212. doi:10.10 $39 / \mathrm{c} 2 \mathrm{cc} 17153 \mathrm{~h}$

82. Zhou J, Du X, Wang J, Yamagata N, Xu B. Enzyme-instructed self-assembly of peptides containing phosphoserine to form supramolecular hydrogels as potential soft biomaterials. Front Chem Sci Eng. 2017;11(4):509-515. doi:10.1007/s11705-0171613-7

83. Gao J, Tang C, Elsawy MA, Smith AM, Miller AF, Saiani A. Controlling self-assembling peptide hydrogel properties through network topology. Biomacromolecules. 2017;18(3):826-834. doi:10.1021/acs.biomac.6b01693

84. Caplan MR, Moore PN, Zhang S, Kamm RD, Lauffenburger DA. Self-assembly of a beta-sheet protein governed by relief of electrostatic repulsion relative to van der Waals attraction. Biomacromolecules. 2000;1(4):627-631. doi:10.1021/bm005586w

85. Caplan MR, Schwartzfarb EM, Zhang S, Kamm RD, Lauffenburger DA. Control of self-assembling oligopeptide matrix formation through systematic variation of amino acid sequence. Biomaterials. 2002;23(1):219-227. doi:10.1016/s014 2-9612(01)00099-0

86. Reyes-Martínez JE, Ruiz-Pacheco JA, Flores-Valdéz MA, Elsawy MA, Vallejo-Cardona AA, Castillo-Díaz LA. Advanced hydrogels for treatment of diabetes. J Tissue Eng Regen Med. 2019;13 (8):1375-1393. doi:10.1002/term.2880

87. Lammi C, Bollati C, Gelain F, Arnoldi A, Pugliese R. Enhancement of the stability and anti-DPPIV activity of hempseed hydrolysates through self-assembling peptide-based Hydrogels. Front Chem. 2018;6:670. doi:10.3389/fchem.2018. 00670

88. Fu M, Zhang C, Dai Y, et al. Injectable self-assembled peptide hydrogels for glucose-mediated insulin delivery. Biomater Sci. 2018;6(6):1480-1491. doi:10.1039/c8bm00006a

89. Lee S, Trinh THT, Yoo M, et al. Self-assembling peptides and their application in the treatment of diseases. Int $J \mathrm{Mol} \mathrm{Sci}$. 2019;20:23. doi:10.3390/ijms20235850

90. Briuglia ML, Urquhart AJ, Lamprou DA. Sustained and controlled release of lipophilic drugs from a self-assembling amphiphilic peptide hydrogel. Int J Pharm. 2014;474(1-2):103-111. doi:10.1016/j.ijpharm.2014.08.025 
91. Kim JH, Jung Y, Kim SH, et al. The enhancement of mature vessel formation and cardiac function in infarcted hearts using dual growth factor delivery with self-assembling peptides. Biomaterials. 2011;32(26):6080-6088. doi:10.1016/j.biomaterials. 2011.05.003

92. MacArthur JW, Purcell BP, Shudo Y, et al. Sustained release of engineered stromal cell-derived factor $1-\alpha$ from injectable hydrogels effectively recruits endothelial progenitor cells and preserves ventricular function after myocardial infarction. Circulation. 2013;128 (11Suppl 1):S79-86. doi:10.1161/CIRCULATIONAHA.112.000343

93. Huang LC, Wang HC, Chen LH, et al. Bioinspired self-assembling peptide hydrogel with proteoglycan-assisted growth factor delivery for therapeutic angiogenesis. Theranostics. 2019;9 (23):7072-7087. doi:10.7150/thno.35803

94. Zhao M, Song C, Zhang W, et al. The three-dimensional nanofiber scaffold culture condition improves viability and function of islets. $J$ Biomed Mater Res A. 2010;94(3):667-672. doi:10.1002/jbm.a.32624

95. Liu S, Zhang L, Cheng J, Lu Y, Liu J. Sustained release of hepatocyte growth factor by cationic self-assembling peptide/ heparin hybrid hydrogel improves $\beta$-cell survival and function through modulating inflammatory response. Int $J$ Nanomedicine. 2016;11:4875-4890. doi:10.2147/IJN.S108921

96. Liu J, Liu S, Chen Y, Zhao X, Lu Y, Cheng J. Functionalized selfassembling peptide improves INS-1 $\beta$-cell function and proliferation via the integrin/FAK/ERK/cyclin pathway. Int $J$ Nanomedicine. 2015;10:3519-3531. doi:10.2147/IJN.S80502

97. Chow LW, Wang LJ, Kaufman DB, Stupp SI. Self-assembling nanostructures to deliver angiogenic factors to pancreatic islets. Biomaterials. 2010;31(24):6154-6161. doi:10.1016/j.biomaterials. 2010.04.002

98. Stendahl JC, Wang LJ, Chow LW, Kaufman DB, Stupp SI. Growth factor delivery from self-assembling nanofibers to facilitate islet transplantation. Transplantation. 2008;86(3):478-481. doi:10.1097/TP.0b013e3181806d9d

99. Yoon YM, Lewis JS, Carstens MR, et al. A combination hydrogel microparticle-based vaccine prevents type 1 diabetes in non-obese diabetic mice. Sci Rep. 2015;5:13155. doi:10. 1038/srep 13155

100. Koch F, Müller M, König F, et al. Mechanical characteristics of beta sheet-forming peptide hydrogels are dependent on peptide sequence, concentration and buffer composition. $R$ Soc Open Sci. 2018;5(3):171562. doi:10.1098/rsos.171562

101. Raza F, Zafar H, Zhu Y, et al. A review on recent advances in stabilizing peptides/proteins upon fabrication in hydrogels from biodegradable polymers. Pharmaceutics. 2018;10:1. doi:10.3390/ pharmaceutics 10010016

102. Lim DJ, Antipenko SV, Anderson JM, et al. Enhanced rat islet function and survival in vitro using a biomimetic self-assembled nanomatrix gel. Tissue Eng Part A. 2011;17(3-4):399-406. doi:10.1089/ten.TEA.2010.0151

103. Gamble A, Pepper AR, Bruni A, Shapiro AMJ. The journey of islet cell transplantation and future development. Islets. 2018;10 (2):80-94. doi:10.1080/19382014.2018.1428511

104. Mohammadi Ayenehdeh J, Niknam B, Hashemi SM, et al. Introducing a new experimental islet transplantation model using biomimetic hydrogel and a simple high yield islet isolation technique. Iran Biomed J. 2017;21(4):218-227. doi:10.18869/ acadpub.ibj.21.4.218

105. Schaschkow A, Sigrist S, Mura C, et al. Glycaemic control in diabetic rats treated with islet transplantation using plasma combined with hydroxypropylmethyl cellulose hydrogel. Acta Biomater. 2020;102:259-272. doi:10.1016/j.actbio.2019.11.047

106. Weaver JD, Headen DM, Aquart J, et al. Vasculogenic hydrogel enhances islet survival, engraftment, and function in leading extrahepatic sites. Sci Adv. 2017;3(6):e1700184. doi:10.1126/ sciadv. 1700184
107. Yang KC, Qi Z, Wu CC, et al. The cytoprotection of chitosan based hydrogels in xenogeneic islet transplantation: an in vivo study in streptozotocin-induced diabetic mouse. Biochem Biophys Res Commun. 2010;393(4):818-823. doi:10.1016/j.bbrc.2010. 02.089

108. Hwang PTJ, Shah DK, Garcia JA, et al. Encapsulation of human islets using a biomimetic self-assembled nanomatrix gel for protection against cellular inflammatory responses. ACS Biomater Sci Eng. 2017;3(9):2110-2119. doi:10.1021/acsbiomaterials.7b 00261

109. Lim DJ, Andukuri A, Vines JB, et al. Enhanced MIN-6 beta cell survival and function on a nitric oxide-releasing peptide amphiphile nanomatrix. Int J Nanomedicine. 2014;9(Suppl 1):13-21. doi:10.2147/IJN.S50873

110. Khan S, Sur S, Newcomb CJ, Appelt EA, Stupp SI. Self-assembling glucagon-like peptide 1-mimetic peptide amphiphiles for enhanced activity and proliferation of insulin-secreting cells. Acta Biomater. 2012;8(5):1685-1692. doi:10.1016/j.actbio.2012.01.036

111. Markey A, Workman VL, Bruce IA, et al. Peptide hydrogel in vitro non-inflammatory potential. J Pept Sci. 2017;23(2):148154. doi:10.1002/psc. 2940

112. Rudra JS, Sun T, Bird KC, et al. Modulating adaptive immune responses to peptide self-assemblies. ACS Nano. 2012;6(2):15571564. doi:10.1021/nn204530r

113. Du X, Zhou J, Shi J, Xu B. Supramolecular hydrogelators and hydrogels: from soft matter to molecular biomaterials. Chem Rev. 2015;115(24):13165-13307. doi:10.1021/acs.chemrev.5b0 0299

114. Chen J, Zou X. Self-assemble peptide biomaterials and their biomedical applications. Bioact Mater. 2019;4:120-131. doi:10. 1016/j.bioactmat.2019.01.002

115. Pellegrinelli V, Heuvingh J, du Roure O, et al. Human adipocyte function is impacted by mechanical cues. J Pathol. 2014;233 (2):183-195. doi:10.1002/path.4347

116. Møller JE, Pellikka PA, Hillis GS, Oh JK. Prognostic importance of diastolic function and filling pressure in patients with acute myocardial infarction. Circulation. 2006;114(5):438-444. doi:10.1161/CIRCULATIONAHA.105.601005

117. Nesto RW, Kowalchuk GJ. The ischemic cascade: temporal sequence of hemodynamic, electrocardiographic and symptomatic expressions of ischemia. Am J Cardiol. 1987;59(7):23C-30C. doi:10.1016/0002-9149(87)90192-5

118. Rivas M, Del Valle LJ, Alemán C, Puiggalí J. Peptide selfassembly into hydrogels for biomedical applications related to hydroxyapatite. Gels. 2019;5:1. doi:10.3390/gels501 0014

119. Reis LA, Chiu LL, Wu J, et al. Hydrogels with integrin-binding angiopoietin-1-derived peptide, QHREDGS, for treatment of acute myocardial infarction. Circ Heart Fail. 2015;8(2):333341. doi:10.1161/CIRCHEARTFAILURE.114.001881

120. Davis ME, Hsieh PC, Takahashi T, et al. Local myocardial insulin-like growth factor 1 (IGF-1) delivery with biotinylated peptide nanofibers improves cell therapy for myocardial infarction. Proc Natl Acad Sci U S A. 2006;103(21):8155-8160. doi:10.1073/ pnas.0602877103

121. Webber MJ, Tongers J, Newcomb CJ, et al. Supramolecular nanostructures that mimic VEGF as a strategy for ischemic tissue repair. Proc Natl Acad Sci U S A. 2011;108(33):13438-13443. doi:10.1073/pnas.1016546108

122. Catoira MC, Fusaro L, Di Francesco D, Ramella M, Boccafoschi F. Overview of natural hydrogels for regenerative medicine applications. J Mater Sci Mater Med. 2019;30(10):115. doi:10.1007/ s10856-019-6318-7

123. Asti A, Gioglio L. Natural and synthetic biodegradable polymers: different scaffolds for cell expansion and tissue formation. Int $J$ Artif Organs. 2014;37(3):187-205. 
124. Aisenbrey EA, Murphy WL. Synthetic alternatives to Matrigel. Nat Rev Mater. 2020;5(7):539-551. doi:10.1038/s41578-020-0199-8

125. Han C, Zhou J, Liang C, et al. Human umbilical cord mesenchymal stem cell derived exosomes encapsulated in functional peptide hydrogels promote cardiac repair. Biomater Sci. 2019;7 (7):2920-2933. doi:10.1039/c9bm00101h

126. Schächinger V, Erbs S, Elsässer A, et al. Intracoronary bone marrow-derived progenitor cells in acute myocardial infarction. $N$ Engl $J$ Med. 2006;355(12):1210-1221. doi:10.1056/NEJMoa060186

127. Wollert KC, Meyer GP, Lotz J, et al. Intracoronary autologous bone-marrow cell transfer after myocardial infarction: the BOOST randomised controlled clinical trial. Lancet. 2004;364 (9429):141-148. doi:10.1016/S0140-6736(04)16626-9

128. Schuleri KH, Amado LC, Boyle AJ, et al. Early improvement in cardiac tissue perfusion due to mesenchymal stem cells. Am J Physiol Heart Circ Physiol. 2008;294(5):H2002-11. doi:10.1152/ ajpheart.00762.2007

129. Orlic D, Kajstura J, Chimenti S, Bodine DM, Leri A, Anversa P. Transplanted adult bone marrow cells repair myocardial infarcts in mice. Ann N Y Acad Sci. 2001;938:221-9; discussion 229-30. doi:10.1111/j.1749-6632.2001.tb03592.x

130. Wu Z, Chen G, Zhang J, et al. Treatment of myocardial infarction with gene-modified mesenchymal stem cells in a small molecular hydrogel. Sci Rep. 2017;7(1):15826. doi:10.1038/s41598-017-15870-Z

131. Li X, Chen YY, Wang XM, et al. Image-guided stem cells with functionalized self-assembling peptide nanofibers for treatment of acute myocardial infarction in a mouse model. Am J Transl Res. 2017;9(8):3723-3731.

132. Guo HD, Cui GH, Wang HJ, Tan YZ. Transplantation of marrowderived cardiac stem cells carried in designer self-assembling peptide nanofibers improves cardiac function after myocardial infarction. Biochem Biophys Res Commun. 2010;399(1):42-48. doi:10.1016/j.bbrc.2010.07.031

133. Puig-Sanvicens VA, Semino CE, Zur Nieden NI. Cardiac differentiation potential of human induced pluripotent stem cells in a 3D self-assembling peptide scaffold. Differentiation. 2015;90(45):101-110. doi:10.1016/j.diff.2015.11.002

134. Soler-Botija C, Bagó JR, Llucià-Valldeperas $\mathrm{A}$, et al. Engineered 3D bioimplants using elastomeric scaffold, selfassembling peptide hydrogel, and adipose tissue-derived progenitor cells for cardiac regeneration. Am J Transl Res. 2014;6 (3):291-301.

135. Chiu YW, Chen WP, Su CC, Lee YC, Hsieh PH, Ho YL. The arrhythmogenic effect of self-assembling nanopeptide hydrogel scaffolds on neonatal mouse cardiomyocytes. Nanomedicine. 2014;10(5):1065-1073. doi:10.1016/j.nano.2014.01.005
136. McClendon MT, Stupp SI. Tubular hydrogels of circumferentially aligned nanofibers to encapsulate and orient vascular cells. Biomaterials. 2012;33(23):5713-5722. doi:10.1016/j.biomaterials. 2012.04.040

137. Kushwaha M, Anderson JM, Bosworth CA, et al. A nitric oxide releasing, self assembled peptide amphiphile matrix that mimics native endothelium for coating implantable cardiovascular devices. Biomaterials. 2010;31(7):1502-1508. doi:10.1016/j. biomaterials.2009.10.051

138. Bomar MG, Samuelsson SJ, Kibler P, Kodukula K, Galande AK. Hemopressin forms self-assembled fibrillar nanostructures under physiologically relevant conditions. Biomacromolecules. 2012;13 (3):579-583. doi:10.1021/bm201836f

139. Zhao Y, Leman LJ, Search DJ, et al. Self-Assembling Cyclic d,1$\alpha$-Peptides as Modulators of Plasma HDL function. A supramolecular approach toward antiatherosclerotic agents. ACS Cent Sci. 2017;3(6):639-646. doi:10.1021/acscentsci.7b00154

140. (IHC) IcfHoTRfPfHU. ICH Guidelines. International council for Harmonisation of Technical Requirements for Pharmaceuticals for Human Use (IHC). https://www.ich.org/ page/ich-guidelines.

141. $\mathrm{Li} \mathrm{X}, \mathrm{Fu} \mathrm{M}, \mathrm{Wu} \mathrm{J}$, et al. $\mathrm{pH}$-sensitive peptide hydrogel for glucose-responsive insulin delivery. Acta Biomater. 2017;51:294-303. doi:10.1016/j.actbio.2017.01.016

142. Jeffcoate WJ, Harding KG. Diabetic foot ulcers. Lancet. 2003;361 (9368):1545-1551. doi:10.1016/S0140-6736(03)13169-8

143. Senturk B, Demircan BM, Ozkan AD, et al. Diabetic wound regeneration using heparin-mimetic peptide amphiphile gel in db/db mice. Biomater Sci. 2017;5(7):1293-1303. doi:10.1039/ c7bm00251c

144. Choe S, Veliceasa D, Bond CW, et al. Sonic hedgehog delivery from self-assembled nanofiber hydrogels reduces the fibrotic response in models of erectile dysfunction. Acta Biomater. 2016;32:89-99. doi:10.1016/j.actbio.2016.01.014

145. Saint-Pierre G, Herrero Gomez M, Martinez Creispera S, et al., New Scaffold for Cardiac Patch. United Kingdom patent application PCT/EP2012/068648. 2014.

146. (ICH) ICfHoTRfPfHU. Quality Guidelines. ICH.

147. (ICH) ICfHoTRfPfHU. Safety Guidelines. ICH.

148. EMA. EMA. Human Cell-Based Medicinal Products. European Medicines Agency (EMA).
International Journal of Nanomedicine

\section{Publish your work in this journal}

The International Journal of Nanomedicine is an international, peerreviewed journal focusing on the application of nanotechnology in diagnostics, therapeutics, and drug delivery systems throughout the biomedical field. This journal is indexed on PubMed Central, MedLine, CAS, SciSearch ${ }^{\mathbb{}}$, Current Contents ${ }^{\mathbb{R}} /$ Clinical Medicine, $^{-}$

\section{Dovepress}

Journal Citation Reports/Science Edition, EMBase, Scopus and the Elsevier Bibliographic databases. The manuscript management system is completely online and includes a very quick and fair peer-review system, which is all easy to use. Visit http://www.dovepress.com/ testimonials.php to read real quotes from published authors. 